\title{
A SURVEY of
}

RESEARCH UTILISATION

NELIUS BOSHOFF

JOHANN MOUTON

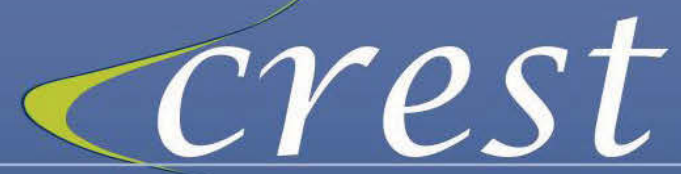

Centre for Research on Science and Technology 
C 


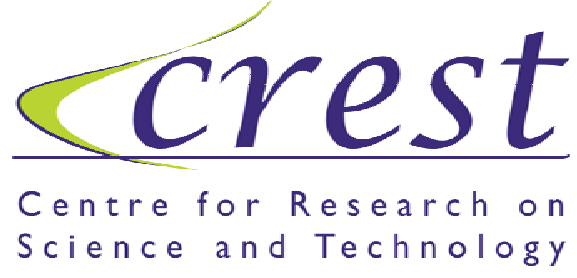

THE PRODUCTION AND UTILISATION OF KNOWLEDGE IN HIGHER EDUCATION INSTITUTIONS IN SOUTH AFRICA

Volume 2

\section{A survey of research utilisation}

Nelius Boshoff \& Johann Mouton

C2005 Centre for Research on Science \& Technology, Stellenbosch University

All rights reserved 
The Production and Utilisation of Knowledge in Higher Education Institutions in South Africa (Volume 2): A Survey of Research Utilisation

Published by SUN PReSS, a division of AFRICAN SUN MeDIA, Stellenbosch 7600

www.africansunmedia.co.za

www.sun-e-shop.co.za

All rights reserved. Copyright $\odot 2005$ Centre for Research on Science \& Technology, Stellenbosch University

No part of this book may be reproduced or transmitted in any form or by any electronic, photographic or mechanical means, including photocopying and recording on record, tape or laser disk, on microfilm, via the Internet, by e-mail, or by any other information storage and retrieval system, without prior written permission by the publisher.

First edition 2005

ISBN: 978-1-919980-62-1

e-ISBN: $978-1-919980-70-6$

DOI: $10.18820 / 9781919980706$

Set in $11 / 13$ Lucida Sans Unicode

Cover design by Dewald van Zyl

Typesetting by Marthie van Niekerk

SUN PReSS is a division of AFRICAN SUN MeDIA, Stellenbosch University's publishing division. SUN PReSS publishes academic, professional and reference works in print and electronic format. This publication may be ordered directly from http://www.sun-e-shop.co.za 


\section{CONTENTS}

Preface i

Chapter I: Introduction

I.I International trends

I.2 Terms of reference

I.3 The theoretical framework

I.4 Outline of the report

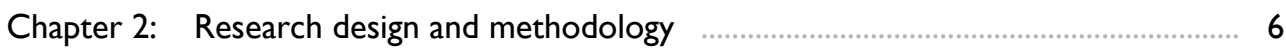

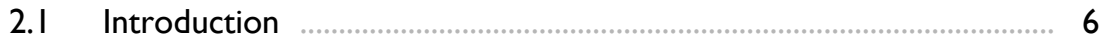

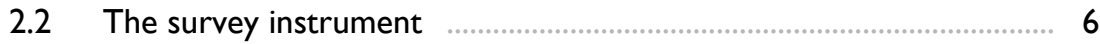

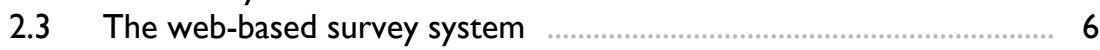

2.3.I Development of a sampling frame ….................................. 6

2.3.2 Development and implementation of the webbased system

2.3.3 Evaluation of the web-based system …................................. 8

2.3.4 Alternative for tertiary institutions that did not provide a list of staff ........................................................ 8

2.3.5 Questionnaire submission rates ......................................... 9

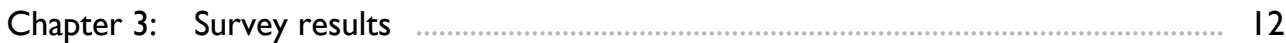

3.I Introduction ........................................................................... 12

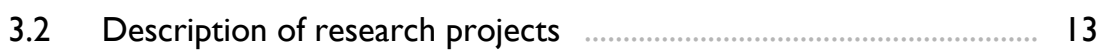

3.2.I The project leader ….................................................. 13

3.2.2 Size of project funding .................................................. 14

3.2.3 Research classification of project activities ...................... 16

3.2.4 Project collaboration ................................................ 17

3.2.5 Expected value or outcome of the project research ........ 18

3.2.6 Intended beneficiaries of the research ........................... 20

3.2.7 Involvement of postgraduate students ............................ 22

3.2.8 Diffusion and dissemination of the project research ........ 23

3.3 Determinants of research utilisation: the results of bivariate analyses ....................................................................... 26

3.3.I Sector of R\&D performance ….................................. 26

3.3.2 Motive or reason for the research …............................. 27

3.3.3 Broad research domain ................................................ 28

3.3.4 Research experience of project leader ............................ $\quad 30$

3.3.5 Time devoted to the project …….................................. 30

3.3.6 Size of project funding …….......................................... 3 I

3.3.7 Project collaboration …............................................. 32

3.3.8 Intended beneficiaries of the research ............................... 33

3.4 Determinants of research utilisation: the results of multivariate analyses

3.4.I Science council and higher education sectors combined 
3.4.2 Science council sector 39

3.4.3 Higher education sector ….......................................

3.4.4 Selected clusters of research domain ………....................... 44

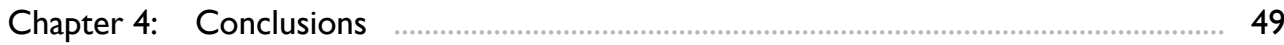

List of references

Appendix A .

Questionnaire: Higher Education Sector ............................................... 60

Questionnaire: Science Councils ................................................................... 65 


\section{PREFACE}

In June 2002, the Carnegie Corporation of New York awarded a substantial grant to CREST - then the Centre for Interdisciplinary Studies - to conduct research on the production and utilisation of research in higher education in South Africa.

In the original proposal to Carnegie, we described the context and rationale behind this project as follows:

With the advent of the new democracy in 1994, it was expected that the higher education institutions in the country would and should play a major role in the transformation of South African society. On the one hand, South African universities and technikons were expected to transform themselves; on the other hand, as major actors within the national system of innovation, it was also expected that they would make a significant contribution to the new society in various ways, including the production of relevant and useful knowledge.

The focus in the project is on the R\&D function of higher education institutions; on the knowledge produced by scientists and scholars at these institutions. In terms of this focus, the overarching aim of the proposed project is to analyse and assess to what extent South African universities and technikons are engaged in a transformative agenda in the production and utilisation of scientific knowledge.

Two major research questions will drive the project:

$<$ To what extent has the production of scientific knowledge at SA universities and technikons changed over the past seven years?

C To what extent is the knowledge produced at SA universities and technikons used, particularly in the interest of new national goals?

At the same time as we commenced our work on this project, the National Advisory Council on Innovation placed on tender a national study on the state of research utilisation in South Africa. CREST was awarded a grant to conduct a survey of public sector R\&D as well as a separate interview-based study of industry views on research utilisation. We subsequently integrated our work on the Carnegie project and the $\mathrm{NACl}$ commission into a two and a half year study. By the end of December 2004 we completed our research.

The findings of this study have been organised into six separate reports:

Volume I: A review of models of research utilisation

Volume 2: A survey of research utilisation

Volume 3: An industry study of the utilisation of public R\&D

Volume 4: The dynamic of knowledge production and utilisation: Fifteen case studies

Volume 5: The role of intermediary organisations in the utilisation of research

Volume 6: Knowledge for transformation: Modes of knowledge production and utilisation in post-apartheid South Africa 
The research team wishes to express its gratitude to the National Advisory Council on Innovation for this commission and especially to $\mathrm{Dr} \mathrm{HC}$ Marais and his staff for their professional support during the study.

We are grateful to all the thousands of respondents who took the time and effort to complete the questionnaires. A special word of thanks is due to all the directors and deans of research at the universities, technikons and science councils who assisted us with the distribution and facilitation of the survey. Without their assistance and support, this study would not have been possible.

A study of this scope invariably relies on teamwork. We have been very fortunate to have a group of dedicated and hard-working individuals who have assisted in various aspects of the study. In particular, we would like to thank the following people:

$<$ Leisl Bowers who assisted with the survey fieldwork.

$<$ Melt van Schoor who designed and managed the web-based data-capturing system for the survey questionnaires and for writing its report.

$<$ Marthie van Niekerk who provided general administrative support to the project.

NELIUS BOSHOFF and JOHANN MOUTON

Stellenbosch 


\subsection{International trends}

The late 1970s saw a fundamental shift in the science policy paradigm. After nearly four decades of science policy studies conducted within a "republic of science" paradigm, international trends (cut-backs in government funding of science, the international oil crisis, massification of higher education and a growing disillusionment with science and technology) led to a new emphasis on strategic science and questions about the use and relevance of scientific knowledge production. One of the outcomes of this "paradigm shift" was a new focus on the utility of science and ways of measuring the benefits of knowledge. The formation of a new journal (Knowledge: Creation, diffusion, utilisation) in 1979 is just one manifestation of the impact of the new way of thinking on science policy scholars.

In a classic paper in the first volume of the new journal, Fritz Machlup (Uses, value and benefits of knowledge) makes a plea for a new approach to measuring the broader economic and social benefits of science. Various subsequent reviews have attempted to map the social and economic benefits of science, including basic research (Hemlin, 1998; Huberman, 1994; Rich, 1997; Salter \& Martin, 200I).

Another stimulus to the debates on knowledge utilisation occurred in the early eighties when the Bayh-Doyle Act (which encouraged universities in the USA to acquire property rights for intellectual outputs) was passed. The whole movement towards linkages and partnerships between academia and business/industry was borne. Phenomena such as science parks, technology transfer offices, technology incubators, spin-off companies and so on have been studied extensively (cf. Carstens \& Mouton, 2002 for a review of this literature). Again the focus is on the various forms of knowledge utilisation and the impact of new forms both on universities and on industry.

At least four theoretical frameworks have informed these empirical studies. The first was the so-called triple-helix model which was developed by Etzkowitz and Leydesdorff; the second is the so-called agora model developed by Remi Barre (Barre, 200I); the third is the more recent publications on the shift from Mode I to Mode 2 knowledge production (Gibbons et al. 1994), and the fourth, is the recent work on "knowledge value alliances" undertaken by Juan Rogers and Barry Bozeman (Rogers \& Bozeman, 200I). Our own empirical study is based largely on the theoretical precepts of Bozeman's work (cf. Theoretical framework below).

\subsection{Terms of reference}

Given the international trends referred to above, it is not surprising that the National Advisory Council on Innovation should commission a national study on research utilisation in South Africa. This is only the second study of its kind in recent years in this country. 
The overall project aims were formulated in the Terms of Reference as follows:

$<$ To ascertain the extent to which SA research findings are utilised/implemented (Component awarded to CREST);

$<$ To map the dynamics of the process of implementation; and

$<$ To develop a model of and strategy for the optimisation of the implementation of research findings.

The scope of the project was delineated by two further requirements in the Terms of Reference:

I) that all major R\&D institutions across all science cultures are included in the study; and

2) that projects completed by such institutions for the period 1997-1998 be included.

We interpreted these two requirements to imply the following:

$<$ That all significant public sector R\&D institutions be included in the study. This means that all current universities (2I) and technikons (I5), science councils (ARC, CSIR, GSC, HSRC, MINTEK, MRC) and the five national facilities be included in the study.

$<$ The time frame (1997-1998) had been selected to ensure that completed projects, where utilisation of research products could already have materialised, be included.

The detailed survey and methodologies that were employed in the public sector study are discussed in Chapter Two.

\subsection{The theoretical framework}

Barry Bozeman's recent work on technology transfer (Bozeman, 2002) formed the main theoretical and analytical framework for the empirical study. The framework informed both the design of the questionnaires for the survey as well as the analysis of the survey and interview data. A detailed discussion of Bozeman's framework was presented in our review of the recent scholarship on research utilisation (Bailey \& Mouton, 2005). We present a summarised version of that discussion here as background to the empirical studies.

Bozeman's aim is to develop a model that explains the effectiveness of technology transfer processes. He refers to his model as the "contingency effectiveness model" because its main point is that technology transfer effectiveness "can have several meanings, including market impacts, political impacts, impacts on personnel involved and impacts on resources available for other purposes and other scientific and technical objectives" (2002:628).

The CETT model incorporates five main dimensions:

I) characteristics of the transfer agent,

2) characteristics of the transfer medium,

3) characteristics of the transfer object,

4) the demand environment, and 
5) (characteristics of the transfer recipient (Cf. Figure I). In Bozeman's own words: ... the model says that the impacts of technology transfer can be understood in terms of who is doing the transfer, how they are doing it, what is being transferred and to whom (idem: 637).

Figure I: The contingency effectiveness model of technology transfer (CETT)

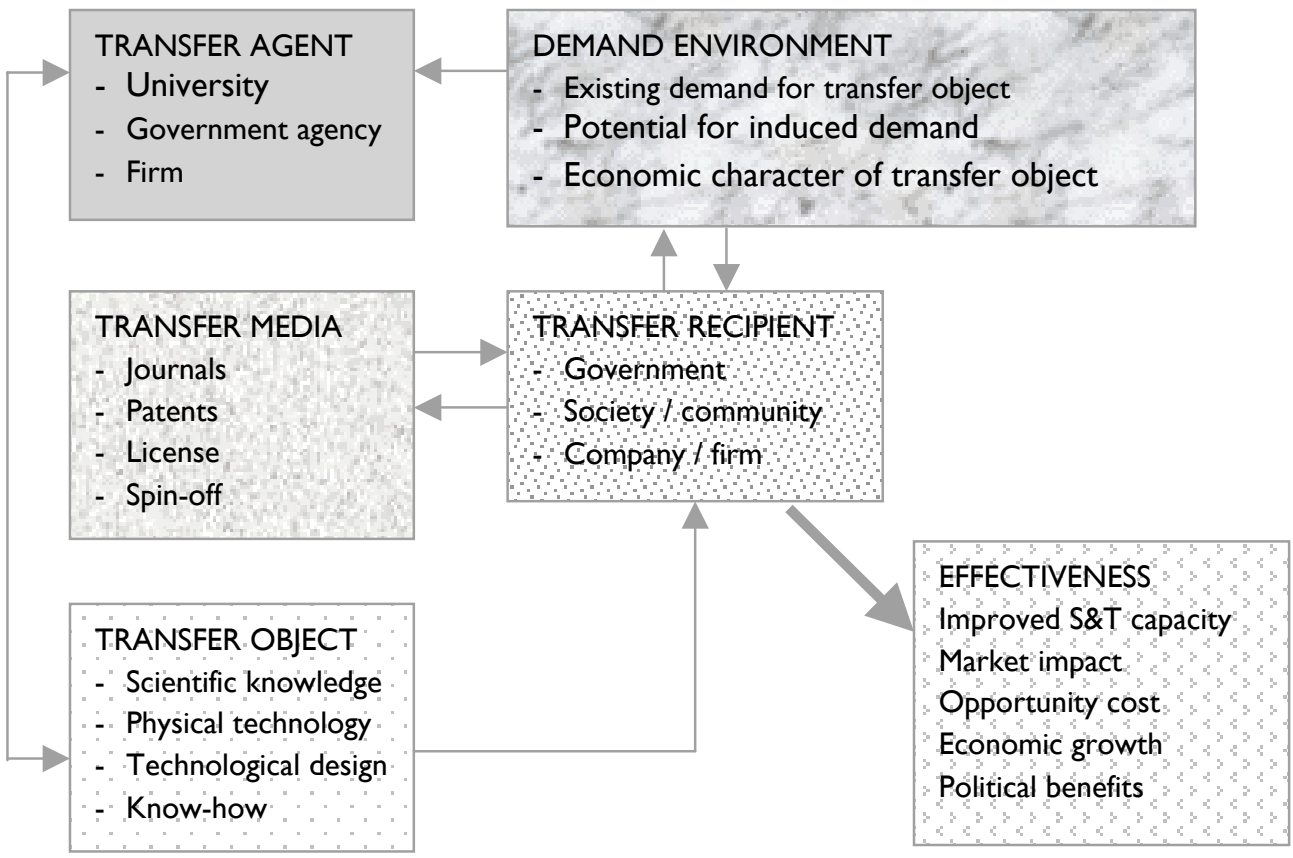

In his review of recent studies on research utilisation, Bozeman discusses the main findings and lessons learnt from this body of scholarship on each of these five dimensions. We summarise some of the most salient conclusions that he draws.

I) Characteristics of the transfer agent

$<$ Etzkowitz $(1994,1998)$ focused on cultural changes within the new entrepreneurial university environment and shows a culture more conducive to industrially relevant work.

$<$ Various studies (e.g. Lee, 1996) found much less enthusiasm amongst university faculty for business partnerships.

C Slaughter and Rhoades (1996) have focused on the effects of the cooperative paradigm on the structure of academic work, including salary distributions by field and faculty research choices. They suggest that more divisions - especially between the humanities and the natural sciences/engineering - are appearing because of these. 
$<$ In earlier studies by Bozeman and Coker (1992) they found that three types of effectiveness related to the transfer agent:

Number of licenses related chiefly to the size of the lab; getting technologies out the door was best explained in terms of the missions of the laboratories and the composition of their R\&D; market impact, measured in terms of commercialized technology, was best explained by research diversity and degree of commercial orientation of the lab. (idem: 640)

2) Characteristics of the transfer medium

$<$ In a comprehensive study of transfer media, Roessner (1993) found that the most important category of interaction was contract research, followed by cooperative research. Few firms valued licensing and more formal interactions.

$<$ The verdict on science parks as a transfer medium remains ambiguous. In a recent study by Felsenstein (1994) it was found that location in a science park seems to provide no direct contribution to innovation but does confer status and prestige and these indirectly promote technology transfer and information flows.

$<$ Not surprisingly, numerous studies increasingly recognize the role of human capital and training in technology transfer. Bozeman refers, amongst others, to work by Bessant and Rush (1995) on consultants, the study of Hicks (1993) on personnel exchange and secondment, and his own work (Bozeman et al 1995) on informal relations among bench-level scientists.

3) Characteristics of the transfer object

$<$ Grant and Gregory (1997) have analysed the transfer of 'tacit knowledge' - an area that is receiving new attention - and found that the extent of transfer of tacit knowledge often has a major impact on the effectiveness of manufacturing technology transfer.

< An issue that has also received much attention is the extent to which transfer objects achieve commercialisation and what is their rate of commercial success. Various studies in the US (Roessner, 1993; Bozeman et al 1995, Geisler and Clements, 1995) have in fact shown that a minority of interactions are motivated by the prospect of directly realized commercial products. In addition, relatively few projects actually results in the company's commercialisation of technology transferred to the company.

$<$ Where commercialisation is successful, Bozeman (1997) has found that projects were more likely to lead to a commercialised product if they were initiated by either the companies' R\&D manager or by top managers in the company.

$<$ Interestingly enough, Rogers and Bozeman (1997) in a study on 219 federal laboratory-industry partnerships, found that projects which involved basic research had higher costs but also a greater likelihood of yielding a commercial technology project. 
4) Characteristics of the demand environment

$<$ It is often assumed that the demand for technology is either market-push or market-pull. However, as Dalpe et al (1002) show, the role of the public sector as the first user of technological innovations is equally important.

$<$ In a study of technology transfer in the biomedical industry, Azzone and Maccarrone (1997) found that the critical demands for technologies and technical competencies is a major factor in determining market impact technology transfer success.

5) Characteristics of the transfer recipient

$<$ According to Bozeman, studies that have compared business and non-profit or government technology recipients have consistently found significant differences in process, barriers to effectiveness and indeed understandings of what count as effectiveness (Kingsley and Farmer, 1997).

$<$ There is evidence that the cooperative technology policy paradigm is taking hold - at least in the US. In their study interviewing companies' research directors and chief technical officers about sources of external technical knowledge, Roessner and Wise (1994) found that universities fared better than federal laboratories or other firms. However, with respect to sources of technical knowledge for new products and production processes, respondents rated in-house R\&D as most important, with universities and government agencies being ranked well below such sources as customers, competitors, suppliers and consultants.

In his final section, Bozeman discusses six effectiveness criteria: "Out of the door" transfer; market impact (e.g. on sales or profitability of the firm); economic development, political effects, opportunity costs and scientific and technical human capital. The advantages and disadvantages of each of these criteria are discussed. At the end of his review, Bozeman points out that despite hundreds of research studies on technology transfer over the recent decades, many topics are still neglected. Although we have learned much, we still know very little about many aspects of the technology transfer process. We quote him in full:

We still know almost nothing about technology transfer politics, including distributional outcomes of technology-based economic development. We have little understanding of many critical impacts, such as developments in scientific and technical human capital, occurring over long time periods. We know little about the impact of technology transfer activities on institutions, their designs and their full range of capabilities. (2000:650)

\subsection{Outline of the report}

Chapter Two is devoted to a discussion of the research design and methodology of the survey. The main results of the questionnaire survey are presented and discussed in Chapter Three. Copies of the questionnaires are attached as Appendix A. 


\subsection{Introduction}

The design employed in this study combined an electronic survey of universities, technikons, science councils and national research facilities with telephone interviews with a sample of industry R\&D managers.

\subsection{The survey instrument}

The survey questionnaire was constructed during July and August 2002. It consists of a short biographical section requesting information on an individual level, and a longer section with a project as the unit of inquiry. The latter includes both aspects of knowledge production (research domain, collaboration etc.) and knowledge utilisation (intended beneficiaries, modes of dissemination etc.). In order to complete the project section, the respondents had to select any research project according to the following criteria:

$<$ The project was completed during the previous five years (completion was taken to mean that results or findings had been generated, and/or that the project had been reported on)

$<$ The respondent was the primary/principal investigator or project leader

$<$ The respondent devoted significant research time and resources to the project.

In addition, the project could have been a stand-alone piece of research or embedded within a longer-term research programme.

A first draft of the instrument was distributed to all members of the larger consortium who collaborated on the $\mathrm{NACl}$ project, and piloted with a few researchers in the higher education and science council sector. After being altered on the basis of feedback and discussions, the instrument was put onto the web server.

\subsection{The web-based survey system}

A web-based survey approach was followed, using as sampling frame the e-mail addresses of research staff at universities, technikons and science councils. In Sections 2.3.I to 2.3.5 below we discuss the procedures used to obtain e-mail addresses from the sampling institutions, as well as the development and implementation of the web-based system, and the questionnaire submission rates.

\subsubsection{Development of a sampling frame}

\section{The higher education sector}

Given the national scope of the survey, and the need to obtain as high as possible a submission rate, it was essential to negotiate the support of the heads of the participating institutions. For universities and technikons it took the form of a personal e-mail, addressed to the Rector or Director of Research, explaining the background and aim of the study. Approval was also sought to send the survey under their name, as well as for 
an electronic file of research/academic staff ( $\mathrm{Cl}$-staff). It was further explained that we would send each person in the file a covering letter via e-mail, together with a hyperlink to the survey questionnaire, which could then be completed on-line. Nine universities and 9 technikons provided us with an electronic list of their $\mathrm{Cl}$-staff.

\section{The science council sector}

Appointments were scheduled with the CEOs and/or senior management personnel of 6 R\&D performing science councils. One of the authors (JM), who facilitated the meetings, used the opportunity to negotiate their assistance, as well as requesting the names and e-mail addresses of research staff. All science councils complied with the request although it had to be followed up with both telephone calls and e-mail reminders.

\subsubsection{Development and implementation of the web-based system}

The survey was set up on an Internet host located at the University of Stellenbosch. The first step was to import the electronic lists of staff into the web-based system's database. In doing so, each individual was automatically assigned a unique user code, making it possible to track responses (and possible technical problems) by respondent. User codes thus served the dual purpose of keeping track of individuals, as well as providing authenticated access to the questionnaire. Moreover, it made it possible to transparently provide access to the correct version of the questionnaire (i.e. the higher education sector version or the science council version), and access to a choice of language (Afrikaans/English) for staff at traditionally Afrikaans institutions.

Once the staff list of an institution had been imported, and the covering letters finalised, the letters were e-mailed to the respondents. Each letter was personalised and contained a unique URL (web address) that gave access to the questionnaire for that person. E-mail recipients accessed the questionnaire by clicking on the link in their e-mail software.

When the correct URL was entered, the respondent directly went to the questionnaire. The respondent then completed the questionnaire in his/her web browser and clicked on a "submit" button at the end of the questionnaire. If submitted successfully, the server captured the user's response and the user was thanked for his/her effort. The server also captured the following:

$<$ The exact time that an e-mail was sent to each respondent

$<$ Whether it was delivered successfully'

$<$ The time that the questionnaire was accessed

$<$ The time that the questionnaire was returned.

The e-mailing of covering letters and hyperlinks happened at various stages during September and October 2002. Reminders were posted towards the end of October 2002, but only to users from whom no questionnaire was received.

I The assumption was made that if the mail system did not return an error, the message was delivered successfully. This does not imply that the person had actually read the message, only that the address is very likely to be valid - similar to regular mail. 


\subsubsection{Evaluation of the web-based system}

Generally, the system worked seamlessly, but there were isolated cases of difficulty. A relatively small number of users complained that they were unable to access the questionnaire, which might have been network-related (e.g. network congestion). Similarly, some respondents' computers had errors or faulty set-up. In all of these cases, there was nothing that we could do but asking respondents to try again or to use an alternative computer and/or Internet access provider.

One problem related to our system concerned the requirement of an active user code. An active code enabled a user to log in to the system and to complete one questionnaire only, after which the code was no longer active. Some users, however, found that the computer had submitted the questionnaire before completion. These users were therefore prevented from going back and completing the questionnaire. In such cases, the incomplete questionnaires had to be manually deleted in order to reactivate the user codes.

At one institution, Mintek, a more serious problem occurred. For a reason as yet undetermined, respondents from Mintek experienced errors when attempting to access and/or return the questionnaire. Since completed questionnaires were becoming lost as a result, we eventually decided to shut down access to the system for Mintek users. They were provided with the alternative of a MS Word version of the questionnaire.

\subsubsection{Alternative for tertiary institutions that did not provide a list of staff}

A number of universities and technikons did not provide us with a list of their $\mathrm{Cl}$-staff, but opted to distribute the covering letter internally, despite our most sincere assurances. An alternative to the system described above therefore had to be developed, since it was no longer possible to link information in a respondent database to invitations or to responses. A special link was provided that facilitated open access (i.e. without a user code) to the questionnaire. Most of the advantages of being able to track respondents were lost in this way for some institutions, but it had the advantage of giving freer access to the questionnaire. 
Tables 2.1 to 2.3 show the questionnaire submission rate by institution.

Table 2.I Questionnaires returned by universities

\begin{tabular}{|c|c|c|c|c|c|c|c|}
\hline University & 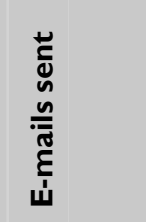 & 高 & 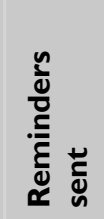 & 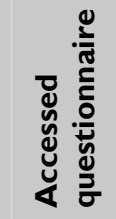 & 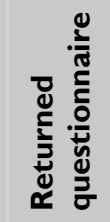 & 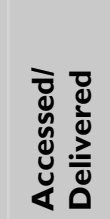 & 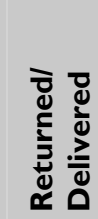 \\
\hline Cape Town' & 447 & 244 & 0 & 40 & 17 & $16 \%$ & $7 \%$ \\
\hline Durban Westville & Unknown & Unknown & -- & I & I & -- & -- \\
\hline \multicolumn{8}{|l|}{ Fort Hare } \\
\hline Free State & 441 & 427 & 355 & 144 & 124 & $34 \%$ & $29 \%$ \\
\hline \multicolumn{8}{|l|}{ Medunsa } \\
\hline Natal & 756 & 741 & 639 & 305 & 176 & $41 \%$ & $24 \%$ \\
\hline North (QwaQwa) & 196 & 117 & 118 & 13 & 6 & $11 \%$ & $5 \%$ \\
\hline \multicolumn{8}{|l|}{ North-West } \\
\hline Port Elizabeth & Unknown & Unknown & -- & 36 & 16 & -- & -- \\
\hline Potchefstroom & 516 & 495 & 399 & 200 & 133 & $40 \%$ & $27 \%$ \\
\hline Pretoria & Unknown & Unknown & -- & 391 & 135 & -- & -- \\
\hline Rand Afrikaans & 368 & 351 & 288 & 135 & 85 & $38 \%$ & $24 \%$ \\
\hline Rhodes & 305 & 274 & 215 & 128 & 96 & $47 \%$ & $35 \%$ \\
\hline South Africal & 1273 & 1230 & 0 & 98 & 61 & $8 \%$ & $5 \%$ \\
\hline Stellenbosch & 769 & 748 & 625 & 312 & 214 & $42 \%$ & $29 \%$ \\
\hline \multicolumn{8}{|l|}{ Transkei } \\
\hline \multicolumn{8}{|l|}{ Venda } \\
\hline Vista & 549 & 460 & 423 & 148 & 87 & $32 \%$ & $19 \%$ \\
\hline Western Cape & Unknown & Unknown & -- & 37 & 9 & -- & -- \\
\hline Witwatersrand & Unknown & Unknown & -- & 100 & 25 & -- & -- \\
\hline Zululand ${ }^{2}$ & 28 & 28 & 25 & 12 & 7 & $43 \%$ & $25 \%$ \\
\hline Total (Known) ${ }^{3}$ & 5648 & 5115 & 3087 & 1535 & 1006 & $30 \%$ & $20 \%$ \\
\hline Total (AII) & -- & -- & -- & 2100 & 1192 & -- & -- \\
\hline
\end{tabular}

Blank cells that are merged mean that the university was not surveyed.

"Unknown" means that the university distributed the e-mails.

I No list of $\mathrm{Cl}$-staff provided. We used e-mail addresses from SA Knowledgebase.

2 E-mails only sent to the Faculty of Science.

3 Universities where the number of e-mails sent/delivered is known. 
Table 2.2 Questionnaires returned by technikons

\begin{tabular}{|c|c|c|c|c|c|c|c|}
\hline Technikon & 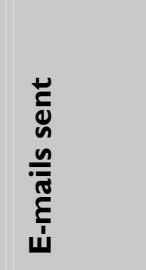 & 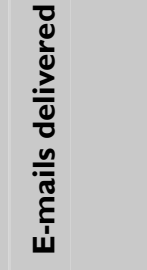 & 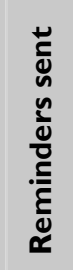 & 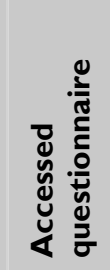 & 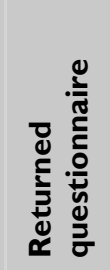 & 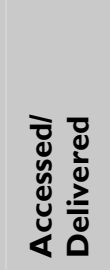 & 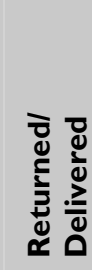 \\
\hline Border & 160 & 158 & 0 & 42 & 20 & $27 \%$ & $13 \%$ \\
\hline Cape & Unknown & Unknown & -- & I & 0 & -- & -- \\
\hline Dbn Inst of Tech & 49 & 45 & 41 & 16 & 10 & $36 \%$ & $22 \%$ \\
\hline \multicolumn{8}{|l|}{ Eastern Cape } \\
\hline Free State & Unknown & Unknown & -- & 3 & I & -- & -- \\
\hline Mangosuthu & 54 & 54 & 52 & 9 & 4 & $17 \%$ & $7 \%$ \\
\hline North. Gauteng & 252 & 242 & 223 & 77 & 32 & $32 \%$ & $13 \%$ \\
\hline \multicolumn{8}{|l|}{ North-West } \\
\hline Peninsula & 224 & 199 & 183 & 56 & 25 & $28 \%$ & $13 \%$ \\
\hline \multicolumn{8}{|l|}{ Pretoria } \\
\hline Port Elizabeth & 278 & 259 & 205 & 128 & 76 & $49 \%$ & $29 \%$ \\
\hline South Africa & 93 & 80 & 63 & 41 & 28 & $51 \%$ & $35 \%$ \\
\hline Vaal Triangle & 63 & 60 & 61 & 39 & 24 & $65 \%$ & $38 \%$ \\
\hline Witwatersrand & 164 & 163 & 149 & 41 & 21 & $25 \%$ & $13 \%$ \\
\hline Total (Known)! & 1337 & 1260 & 977 & 449 & 240 & $36 \%$ & $19 \%$ \\
\hline Total (AlI) & -- & -- & -- & 453 & 241 & -- & -- \\
\hline
\end{tabular}

Blank cells that are merged mean that the technikon was not surveyed.

"Unknown" means that the technikon distributed the e-mails.

I Technikons where the number of e-mails sent/delivered is known. 
Table 2.3 Questionnaires returned by science councils

\begin{tabular}{|c|c|c|c|c|c|c|c|}
\hline Institution & 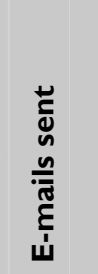 & 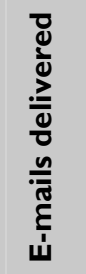 & 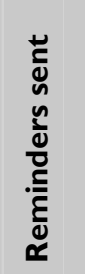 & 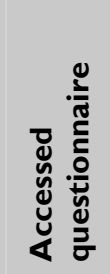 & 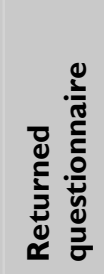 & 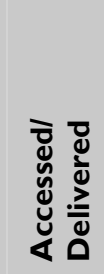 & 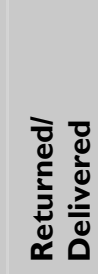 \\
\hline ARC & 872 & 773 & 669 & 351 & 206 & $45 \%$ & $27 \%$ \\
\hline CSIR & 1185 & 1185 & 1023 & 552 & 273 & $47 \%$ & $23 \%$ \\
\hline Geoscience & 139 & 139 & 122 & 82 & 51 & $59 \%$ & $37 \%$ \\
\hline HSRC & 111 & 92 & 74 & 42 & 25 & $46 \%$ & $27 \%$ \\
\hline Mintek' & 202 & 166 & 0 & 95 & 25 & $57 \%$ & $15 \%$ \\
\hline MRC & 336 & 185 & 161 & 105 & 43 & $57 \%$ & $23 \%$ \\
\hline SAAO & 14 & 14 & 13 & 7 & 2 & $50 \%$ & $14 \%$ \\
\hline Total & 2859 & 2554 & 2062 & 1234 & 625 & $48 \%$ & $24 \%$ \\
\hline
\end{tabular}

I We have captured the completed questionnaires for Mintek manually onto the system.

A total of 2058 questionnaires was received. In Section 3.2.2 we examine the extent to which the projects in the sample represent the universe of projects in the higher education and science council sectors for 2000 . 


\subsection{Introduction}

The key findings of the public sector survey into research utilisation is presented and discussed under three sections. In the first section, the key features of the reported projects are discussed with reference to the following:

$<$ The project leader

$<$ Size of project funding

$<$ Research classification of project activities

$<$ Project collaboration

$<$ Expected value or outcome of the project research

$<$ Intended beneficiaries of the research

$<$ Involvement of postgraduate students

$<$ Diffusion and dissemination of the project research

The second main section of Chapter 3 is devoted to a discussion of the bivariate analyses of the data. The following variables were cross-tabulated with the key dependent variable of the study: whether the utilisation of research findings has been effective or not.

$<$ Sector of R\&D performance

$<$ Motive or reason for the research

$<$ Broad research domain

$<$ Research experience of project leader

$<$ Time devoted to the project

$<$ Size of project funding

$<$ Project collaboration

$<$ Intended beneficiaries of the research

In the final section of Chapter 3, we present the results of a number of multivariate (CHAID) analyses, where the following variables were analysed in their relationship to effective utilisation:

$<$ Broad research domain

$<$ Research experience of project leader

$<$ Time devoted to the project

$<$ Size of project funding

$<$ Project collaboration 
These analyses were done separately for the higher education sector and the science council sector.

\subsection{Description of research projects}

As highlighted in the methodology section, a total of 2058 questionnaires was received, of which the majority (58\%) are in the university sector (Table 2.I). Since the research project is the unit of analysis, our analyses are based on the subset of 1803 respondents ( $88 \%$ of total) who provided details about their research projects.

Table 3.I Survey respondents and research projects by sector of R\&D performance

\begin{tabular}{|l|l|l|l|l|}
\hline Sector & Respondents & & Projects & \\
\hline S & N & $\%$ & N & $\%$ \\
\hline Univence councils & 625 & 30 & 539 & 30 \\
\hline Technikies & 1192 & 58 & 1081 & 60 \\
\hline Total & 241 & 12 & 183 & 10 \\
\hline
\end{tabular}

In sections 3.2.I to 3.2.8 we consider various aspects of the research projects.

\subsubsection{The project leader}

Table 3.2 gives the profile of the project leaders in terms of gender, highest educational qualification completed, age and years of research experience. The breakdown is per sector. 
Table 3.2 Basic profile of project leaders, per sector

\begin{tabular}{|c|c|c|c|c|}
\hline Variables & All sectors & Science councils & Universities & Technikons \\
\hline \multicolumn{5}{|c|}{ CATEGORICAL VARIABLES (\%) } \\
\hline \multicolumn{5}{|l|}{ Gender } \\
\hline Female & 37 & 32 & 38 & 43 \\
\hline Male & 63 & 68 & 62 & 57 \\
\hline \multicolumn{5}{|c|}{ Highest qualification } \\
\hline Bachelors/ HDip & 5 & 13 & $\mathbf{I}$ & II \\
\hline Honours & 9 & 13 & 6 & II \\
\hline Masters & 31 & 39 & 24 & 51 \\
\hline Doctorate & 52 & 31 & 66 & 25 \\
\hline Other & 3 & 4 & 3 & 2 \\
\hline \multicolumn{5}{|c|}{ SCALE VARIABLES (in years) } \\
\hline \multicolumn{5}{|l|}{ Age } \\
\hline Mean & 43.8 & 41.3 & 45.2 & 43.3 \\
\hline Median & 44.0 & 41.0 & 46.0 & 43.0 \\
\hline \multicolumn{5}{|c|}{ Research experience } \\
\hline Mean & 13.7 & I4.I & 14.5 & 7.6 \\
\hline Median & 12.0 & I3.0 & 12.0 & 5.0 \\
\hline
\end{tabular}

As expected, the project leaders are predominantly male (more so however in science councils and universities than in technikons). Those in the technikon sector have recorded the least research experience (a median of 5 years versus 12 - I 3 years for the other sectors). Also, markedly more projects leaders at universities have doctoral degrees than those at technikons and science councils. The average age across the sample is about 44 years.

\subsubsection{Size of project funding}

The project leaders specified the amount of funding received for the project, which includes all grants, awards and contract monies. These are shown in Table 3.3. 


\section{Table 3.3 Project funding per sector}

\begin{tabular}{|c|c|c|}
\hline Funding category & $\mathbf{N}$ & $\%$ \\
\hline \multicolumn{3}{|l|}{ Higher education sector } \\
\hline Less than R50 000 & 672 & 57.7 \\
\hline R50 000 - R99 000 & I4I & I2.1 \\
\hline R100 $000-R 249000$ & 140 & 12.0 \\
\hline R250 000 - R499 000 & 72 & 6.2 \\
\hline R500 000 - R999000 & 64 & 5.5 \\
\hline RI $000000-R 2000000$ & 43 & 3.7 \\
\hline More than R2 000000 & 33 & 2.8 \\
\hline Total & 1165 & 100.0 \\
\hline \multicolumn{3}{|l|}{ Science council sector } \\
\hline Less than R250 000 & 217 & 42.1 \\
\hline R250 000 - R499 000 & 96 & 18.6 \\
\hline R500 000 - R999 000 & 78 & I5.I \\
\hline RI $000000-R$ I 999000 & 50 & 9.7 \\
\hline R2 $000000-R 5000000$ & 38 & 7.4 \\
\hline More than R5 000000 & 37 & 7.2 \\
\hline Total & 516 & 100.0 \\
\hline
\end{tabular}

Apart from throwing light on the size and scope of projects, project funding can also be used to determine the extent of sample representation - the extent to which the sample actually reflects the universe of projects in the higher education and science council sectors. We have done so by expressing the total project funding as a percentage of public R\&D expenditure.

For any project an exact funding amount was calculated by using the interval mid-point as estimate. This gives a total funding of R79I.6 million, based on I 68I projects. If we replace the missing values for each sector by its modal funding (the value with the highest frequency), the total project funding amounts to R799.2 million (R535.5 million for science councils and R263.7 million for higher education). However, this covers all projects in their total duration, which may be more than 30 years in some cases. Also, not all the projects have the same years in common (e.g. some started in 1995 but ended in 1999 whereas others started in $200 \mathrm{I}$ and are still ongoing). The year that the majority of projects ( $N=$ I 148 or $64 \%$ of total) have in common is 2000 . Thus, if we want to obtain an estimate of our coverage of projects in terms of its share of public R\&D expenditure it would be best to use 2000 as reference year as shown in Table 3.4. 
Table 3.4 Project funding for $\mathbf{2 0 0 0}$ as a percentage of total R\&D expenditure ( $\mathbf{R}$ millions)

\begin{tabular}{|l|l|l|l|}
\hline Sector & $\begin{array}{l}\text { Project funding } \\
\text { for } 2000\end{array}$ & $\begin{array}{l}\text { Total R\&D expenditure } \\
\text { for } 2000\end{array}$ & $\begin{array}{l}\text { Project as \% of } \\
\text { total R\&D }\end{array}$ \\
\hline $\begin{array}{l}\text { Science councils } \\
(\mathrm{N}=350)\end{array}$ & 371.0 & 1770.0 & $21 \%$ \\
\hline $\begin{array}{l}\text { Higher education } \\
(\mathrm{N}=798)\end{array}$ & 202.3 & 1100.0 & $18 \%$ \\
\hline Total $(\mathrm{N}=1$ I 148) & 573.3 & 2870.0 & $20 \%$ \\
\hline
\end{tabular}

According to Table 3.4 our sample of projects, in terms of funding for 2000 , covers about $20 \%$ of all public R\&D expenditure in the higher education and science council sectors. (The figures for total R\&D expenditure are from a chapter on science policy indicators that CREST has submitted to the HSRC for the latter's HRD Review.)

\subsubsection{Research classification of project activities}

The project leaders were asked to indicate in which broad research domain their research activities mainly fall. Eighteen domains were provided and they could tick as many as applying to their project. Table 3.5 gives the results (in terms of percentages) per sector.

Table 3.5 Broad research domain of project activities, per sector

\begin{tabular}{|c|c|c|c|c|}
\hline Domain & All sectors & Science councils & Universities & Technikons \\
\hline Social sciences & 24.6 & 12.4 & 29.2 & 32.8 \\
\hline Applied sciences \& technologies & 19.2 & 33.4 & 11.8 & 21.3 \\
\hline Arts and humanities & 19.1 & 3.2 & 26.3 & 24.0 \\
\hline Agricultural sciences & 18.2 & 37.7 & 10.8 & 4.9 \\
\hline Health sciences & 16.7 & I4.I & 19.1 & 10.4 \\
\hline Biological sciences & 16.6 & 23.6 & 15.2 & 4.9 \\
\hline Environmental sciences & 15.6 & 27.3 & 10.4 & 12.0 \\
\hline Economic \& management sciences & 13.9 & 9.8 & I5.I & 18.6 \\
\hline Engineering sciences & 12.0 & 21.2 & 7.4 & 12.6 \\
\hline $\begin{array}{l}\text { Information \& communication } \\
\text { technologies }\end{array}$ & 7.9 & 9.6 & 6.3 & 12.6 \\
\hline Earth sciences & 7.3 & 16.0 & 3.7 & 3.3 \\
\hline Chemical sciences & 7.2 & II.I & 5.1 & 7.7 \\
\hline Medical sciences: Basic & 5.1 & 3.7 & 6.3 & 2.2 \\
\hline Mathematical sciences & 4.9 & 4.5 & 5.0 & 6.0 \\
\hline Material sciences & 4.3 & 5.8 & 3.2 & 6.0 \\
\hline Physical sciences & 4.3 & 3.9 & 4.3 & 4.9 \\
\hline Medical sciences: Clinical & 3.7 & 3.2 & 4.2 & 2.2 \\
\hline Marine sciences & 2.1 & 3.2 & 1.9 & 0.0 \\
\hline
\end{tabular}


The projects housed at science councils largely fall within the domain of agricultural sciences (37.7\%), applied sciences and technologies (33.4\%), and environmental sciences $(27.3 \%)$. The social sciences $(29.2 \%$ and $32.8 \%)$ and arts and humanities $(26.3 \%$ and $24.0 \%$ ) rank among the top two domains at the higher education institutions. Health sciences (19.1\%) and applied sciences and technologies (21.3\%) rank third at universities and technikons respectively. The broad research domains were subsequently classed into three science culture categories (SS = social sciences, NS = natural sciences, $\mathrm{H} \& M S=$ health and medical sciences $)^{2}$ and possible combinations thereof. These are displayed in Table 3.6.

Table 3.6 Science culture of project activities, per sector

\begin{tabular}{|c|c|c|c|c|c|c|c|c|}
\hline \multirow{2}{*}{ Science culture } & \multicolumn{2}{|c|}{ All sectors } & \multicolumn{2}{|c|}{ Science councils } & \multicolumn{2}{|c|}{ Universities } & \multicolumn{2}{|c|}{ Technikons } \\
\hline & $\mathbf{N}$ & $\%$ & $\mathbf{N}$ & $\%$ & $\mathbf{N}$ & $\%$ & $\mathbf{N}$ & $\%$ \\
\hline NS & 735 & 41 & 371 & 69 & 307 & 29 & 57 & 31 \\
\hline SS & 540 & 30 & 26 & 5 & 437 & 41 & 77 & 43 \\
\hline SS / NS & 168 & 10 & 52 & 10 & 91 & 8 & 25 & 14 \\
\hline H\&MS & 135 & 8 & 20 & 4 & 106 & 10 & 9 & 5 \\
\hline H\&MS / NS & 110 & 6 & 40 & 7 & 63 & 6 & 7 & 4 \\
\hline SS / H\&MS & 59 & 3 & II & 2 & 46 & 4 & 2 & I \\
\hline SS / H\&MS / NS & 42 & 2 & 16 & 3 & 22 & 2 & 4 & 2 \\
\hline Total & 1789 & 100 & 536 & 100 & 1072 & 100 & 181 & 100 \\
\hline
\end{tabular}

It is apparent from Table 3.6 that projects associated with a single science culture are prominent within all sectors. In the case of science councils it is mostly natural sciences projects $(69 \%)$. For higher education institutions it is projects of a social sciences nature ( $41 \%$ and $43 \%$ for universities and technikons), followed by natural sciences projects $(29 \%$ and $31 \%)$.

\subsubsection{Project collaboration}

Information was also obtained as to whether or not the project leaders collaborated with others on the project. As can be seen in Figure 3.I, the highest incidence of collaborative activities (87\%) occurred in the science council sector.

$2 \mathrm{SS}=$ Arts and Humanities, Economic and Management Sciences, Social Sciences H\&MS = Health Sciences, Medical Sciences: Basic \& Clinical NS = All the others 
Figure 3.I Incidence of research collaboration, per sector

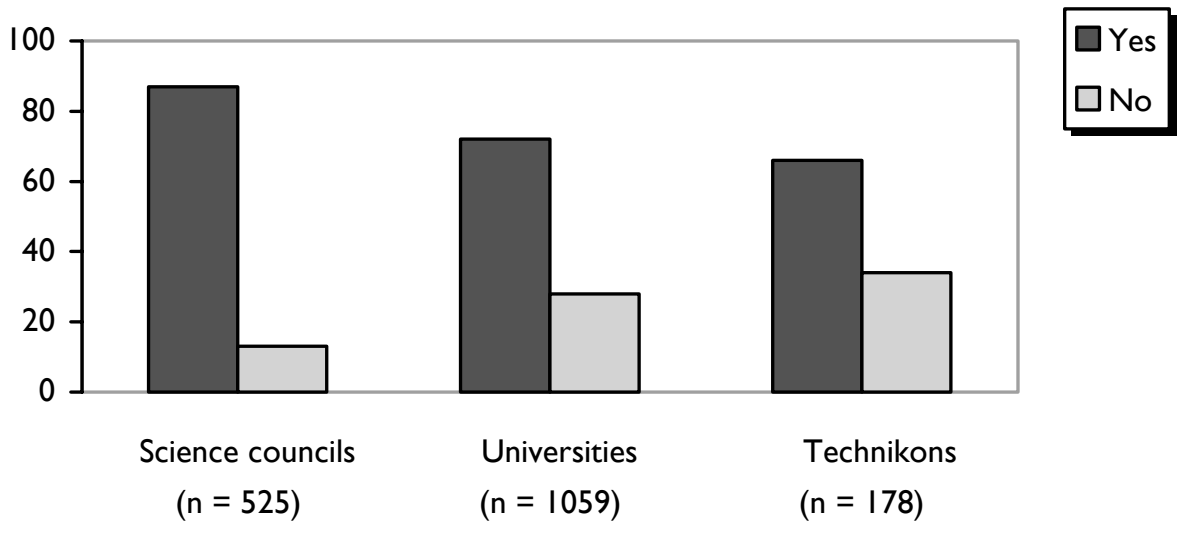

In which sectors do the collaborators work? According to Table 3.7 the collaborators are mostly fellow academics and scholars, although less so for technikons. Also, science councils have the greatest variation in collaboration, as they have the highest incidences of collaboration with industry/business, government, other sciences councils and NGOs.

Table 3.7 Sector of collaboration, per institutional classification

\begin{tabular}{|l|l|l|l|l|l|l|l|l|}
\hline \multirow{2}{*}{ Collaborated with... } & All sectors & \multicolumn{4}{c}{ Science councils Universities } & \multicolumn{2}{l|}{ Technikons } \\
\hline Academics / scholars & I & N & N & $\%$ & N & $\%$ & N & $\%$ \\
\hline Industry/ business & 422 & 23.7 & 300 & 55.7 & 685 & 63.4 & 9 I & 49.7 \\
\hline Government & 284 & 15.8 & 144 & 26.7 & 115 & 10.6 & 25 & 13.7 \\
\hline Science council(s) & 231 & 12.8 & 179 & 33.2 & 46 & 4.3 & 6 & 3.3 \\
\hline NGOs & 160 & 8.9 & 70 & 13.0 & 75 & 6.9 & 15 & 8.2 \\
\hline
\end{tabular}

\subsubsection{Expected value or outcome of the project research}

The project leaders could select from a list of 13 potential outcomes those three that, in their opinion, best describe the overall expected value or outcome of the research. From Table 3.8 it is clear that "advancing or improving knowledge" was the single most important expected outcome in all sectors (ranging between $63.4 \%$ and $72.2 \%$ ). In the higher education sector the development of skills and competencies and the training of students assumed second and third places (although in reversed order for universities and technikons). Skills and competency development also ranks highly in the science council sector, together with solving of immediate technical and applied problems. 
Table 3.8 Expected value/ outcome of the research, per sector

\begin{tabular}{|c|c|c|c|c|}
\hline Expected value / outcome & All sectors & Science council & University & Technikon \\
\hline Advancement in knowledge & 69.5 & 66.0 & 72.2 & 63.4 \\
\hline $\begin{array}{l}\text { Development of skills and } \\
\text { competencies }\end{array}$ & 33.0 & 34.0 & 32.0 & 36.1 \\
\hline Training of students & 29.7 & 10.6 & 38.6 & 33.9 \\
\hline $\begin{array}{l}\text { Solving immediate technical applied } \\
\text { problems }\end{array}$ & 24.3 & 39.0 & 17.7 & 20.2 \\
\hline Influenced decision-makers & 21.7 & 23.6 & 21.2 & 19.1 \\
\hline $\begin{array}{l}\text { Solving environmental or social } \\
\text { problems }\end{array}$ & 21.2 & 25.2 & 19.3 & 20.2 \\
\hline $\begin{array}{l}\text { Change in behaviour/ attitudes/ } \\
\text { values }\end{array}$ & 18.7 & 11.5 & 20.8 & 27.9 \\
\hline Development of new technology & 14.4 & 23.4 & 9.9 & 14.8 \\
\hline Solving of theoretical problems & 13.1 & 8.9 & 16.1 & 7.7 \\
\hline $\begin{array}{l}\text { Improved product or technical } \\
\text { design }\end{array}$ & 8.3 & 12.2 & 6.6 & 7.1 \\
\hline Change legislation & 4.0 & 5.2 & 3.7 & 2.2 \\
\hline Entrance into new markets & 3.4 & 6.9 & 1.9 & 2.7 \\
\hline Engineered a prototype & 3.1 & 4.5 & 2.4 & 2.7 \\
\hline
\end{tabular}

For each outcome or value selected, the project leader indicated the extent to which he/she believed that the outcome has been successfully attained. Three options were given: highly successful, successful to some extent, and not successful at all (Table 3.9).

Table 3.9 Successful attainment of research outcome

\begin{tabular}{|c|c|c|c|c|c|}
\hline \multirow[b]{2}{*}{ Expected value / outcome } & \multicolumn{4}{|c|}{ Successful (\%) } & \multirow{2}{*}{$\begin{array}{l}\text { Number of } \\
\text { projects }\end{array}$} \\
\hline & Highly & $\begin{array}{l}\text { To some } \\
\text { extent }\end{array}$ & $\begin{array}{l}\text { Not at } \\
\text { all }\end{array}$ & $\begin{array}{l}\text { No } \\
\text { response }\end{array}$ & \\
\hline $\begin{array}{l}\text { Advancement or improvement in } \\
\text { knowledge }\end{array}$ & 67.7 & 30.3 & 0.4 & 1.6 & 1253 \\
\hline Training of students & 66.6 & 30.8 & 0.6 & 2.0 & 536 \\
\hline Engineered a prototype & 60.0 & 34.5 & 0.0 & 5.5 & 55 \\
\hline Development of skills and competencies & 56.8 & 40.0 & 1.7 & 1.5 & 595 \\
\hline Development of new technology & 53.5 & 43.1 & 1.9 & 1.5 & 260 \\
\hline Improved product or technical design & 53.3 & 41.3 & 3.3 & 2.1 & 150 \\
\hline $\begin{array}{l}\text { Solving immediate technical / applied } \\
\text { problems }\end{array}$ & 52.7 & 45.2 & 0.7 & 1.4 & 438 \\
\hline
\end{tabular}


Table 3.9 Continued

\begin{tabular}{|l|l|l|l|l|l|}
\hline Expected value / outcome & Highly & $\begin{array}{l}\text { To some } \\
\text { extent }\end{array}$ & $\begin{array}{l}\text { Not at } \\
\text { all }\end{array}$ & $\begin{array}{l}\text { No } \\
\text { response }\end{array}$ & $\begin{array}{l}\text { Number of } \\
\text { projects }\end{array}$ \\
\hline Solving of theoretical problems & 41.9 & 53.4 & 0.8 & 3.9 & 236 \\
\hline Entrance into new markets & 37.1 & 53.2 & 8.1 & 1.6 & 62 \\
\hline Influenced decision-makers & 28.4 & 58.8 & II.0 & 1.8 & 39 I \\
\hline $\begin{array}{l}\text { Solving environmental or social } \\
\text { problems }\end{array}$ & 27.7 & 65.4 & 5.0 & 1.9 & 382 \\
\hline Change in behaviour/ attitudes/ values & 27.2 & 64.8 & 6.2 & 1.8 & 338 \\
\hline Change legislation & 18.1 & 58.3 & 19.4 & 4.2 & 72 \\
\hline
\end{tabular}

Not surprisingly, the rankings in Table 3.9 reveal that project outcomes, which are more under the "control" of the principal investigator, such as the advancement of knowledge or capacity building are more likely to be successfully attained. Conversely where projects outcomes relate to a form of broader social intervention (such as changing legislation, values, or solving environmental or social problems) or change in behaviour, the expected success rate is much lower. Another dimension that seems to underpin these results is whether the expected outcome is of a more theoretical/conceptual nature (advancing knowledge) or of a more practical/applied nature (solving problems). In this case, it appears as if projects with more theoretical/conceptual outcomes are also seen as more likely to successfully have attained their outcomes.

\subsubsection{Intended beneficiaries of the research}

Table 3. 10 indicates which intended beneficiaries the project leaders had in mind when they conceptualised the research.

Table 3.10 Those intended to benefit by the research

\begin{tabular}{|l|l|l|}
\hline Intended beneficiary & N & $\%$ \\
\hline Colleagues/scholars/peers in own discipline & $\mathbf{1 0 7 9}$ & $\mathbf{5 9 . 8}$ \\
\hline General public/ society/ community & $\mathbf{5 5 3}$ & 30.7 \\
\hline Industry/ firms & $\mathbf{5 4 6}$ & 30.3 \\
\hline Specific interest groups (e.g. farmers, consumers) & 530 & 29.4 \\
\hline Government & $\mathbf{5 1 4}$ & $\mathbf{2 8 . 5}$ \\
\hline Colleagues/scholars/peers in other disciplines & $\mathbf{4 6 6}$ & $\mathbf{2 5 . 8}$ \\
\hline The contracting agency & $\mathbf{2 7 I}$ & 15.0 \\
\hline
\end{tabular}

In Table 3.10 the majority of project leaders said that they expect colleagues or scholars in their own discipline to benefit from the research. This is not surprising, given the prominence of advancement or improvement in knowledge as a project outcome. Only in 
I5\% of cases has the contracting agency been reported as an intended beneficiary. The distribution of responses by sector is shown in Table 3.II.

Table 3.II Intended beneficiaries, per sector

\begin{tabular}{|c|c|c|c|c|c|c|}
\hline \multirow{2}{*}{ Intended beneficiary } & \multicolumn{2}{|c|}{ Science councils } & \multicolumn{2}{|c|}{ Universities } & \multicolumn{2}{|c|}{ Technikons } \\
\hline & $\mathbf{N}$ & $\%$ & $\mathbf{N}$ & $\%$ & $\mathbf{N}$ & $\%$ \\
\hline Colleagues/scholars/peers in own discipline & 228 & 42.3 & 739 & 68.4 & 112 & 61.2 \\
\hline Colleagues/scholars/peers in other disciplines & 97 & 18.0 & 326 & 30.2 & 43 & 23.5 \\
\hline The contracting agency & 126 & 23.4 & 135 & 12.5 & 10 & 5.5 \\
\hline Industry/ firms & 225 & 41.7 & 250 & 23.1 & 71 & 38.8 \\
\hline Government & 206 & 38.2 & 262 & 24.2 & 46 & 25.1 \\
\hline Specific interest groups (e.g. farmers, consumers) & 222 & 41.2 & 275 & 25.4 & 33 & 18.0 \\
\hline General public/ society/ community & 172 & 31.9 & 330 & 30.5 & 51 & 27.9 \\
\hline
\end{tabular}

Colleagues in one's own discipline are more likely to be specified as intended beneficiaries in the two sectors of higher education, compared to the science council sector $(68.4 \%$ and $61.2 \%$ versus $42.3 \%$ ). Colleagues in other disciplines also feature strongest in the university sector. There appears a greater tendency for technikons and science councils to identify industry and firms as beneficiaries. Also, science councils have a relatively larger component of projects directed at specific interest groups.

Did the intended beneficiaries recognise or utilise the research as planned? Of the I 749 project leaders who responded to this question, $57 \%$ said yes, the intended beneficiaries did to some extent (Figure 3.2).

Figure 3.2 Did the intended beneficiaries recognise/ utilise/ implement the research as planned?

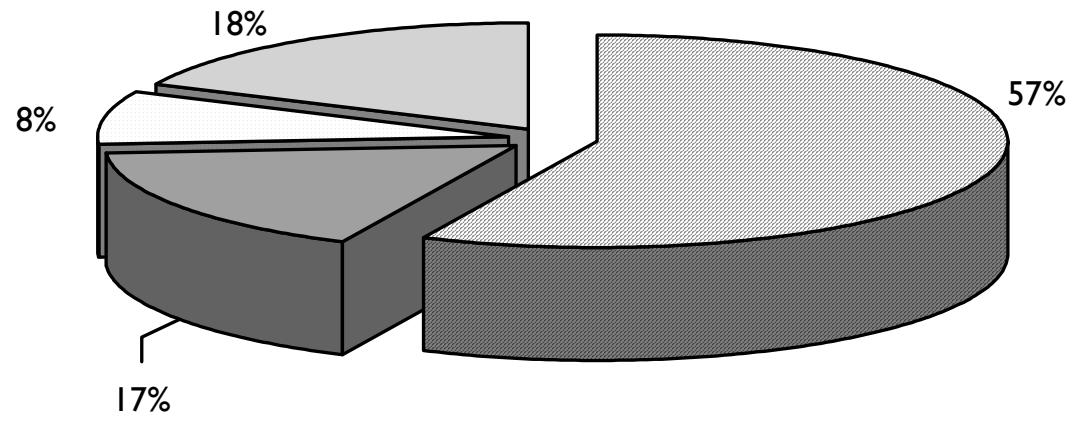

Yes, to some extent $\square$ Yes, to little extent No, not at all Don't know 
A breakdown by sector appears in Figure 3.3. Here the extent of research utilisation is greatest for science councils, followed by universities and technikons.

Figure 3.3 Utilisation of research by intended beneficiaries, per sector

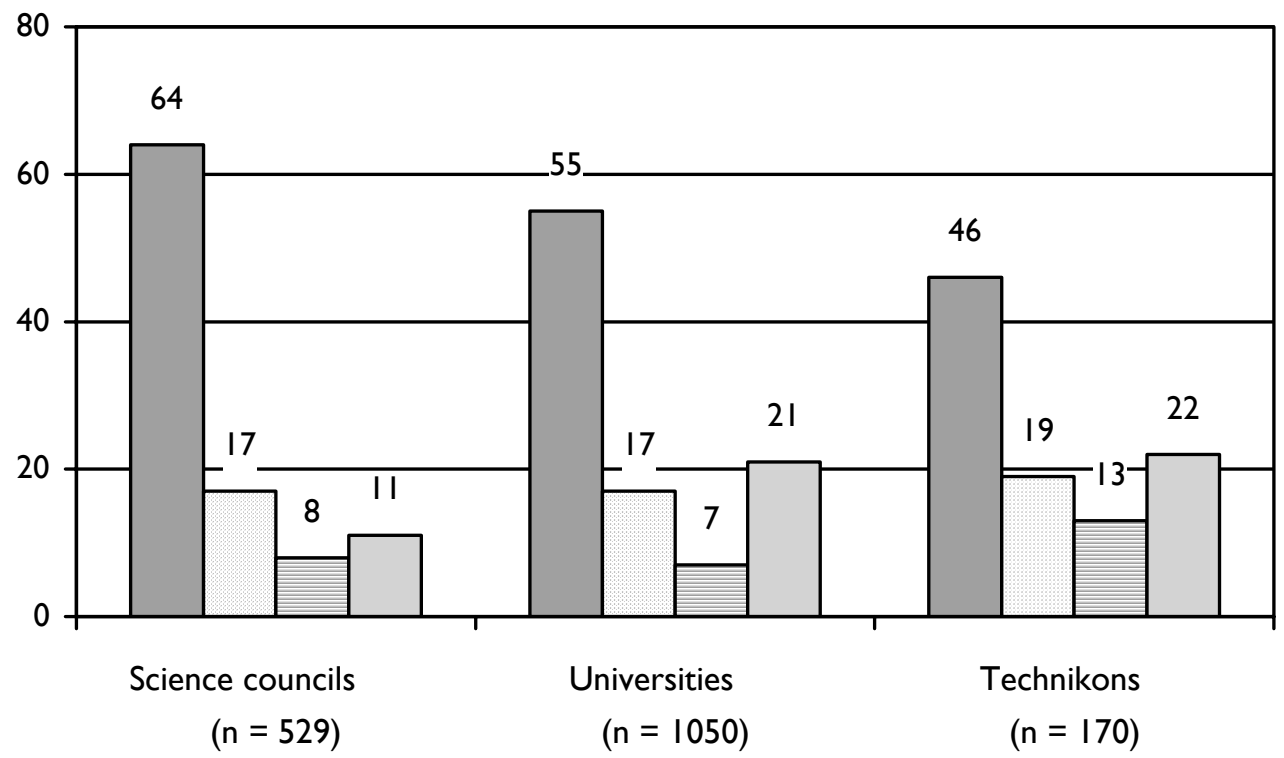

$\square$ Yes, to some extent $\square$ Yes, to little extent $\square$ No, not at all $\square$ Don't know

\subsubsection{Involvement of postgraduate students}

Postgraduate students more than often play an integral role in the utilisation of research; apart from being intended beneficiaries (through skills development etc.) they also act as transfer agents in the sense that the (tacit) skills and knowledge acquired on the project are transferred to and drawn upon in their work environment. We therefore asked the project leaders whether any postgraduate students worked on the project (Figure 3.4), and if so, how many masters and doctoral students received (or were expected to receive) their degree because of the research (Table 3.12).

As can be seen in Figure 3.4 more students worked on university projects than on science council and technikon projects. On average, however, the larger number of doctoral students graduating from the project appears to be in the technikon sector. 
Figure 3.4 Involvement of postgraduate students, per sector

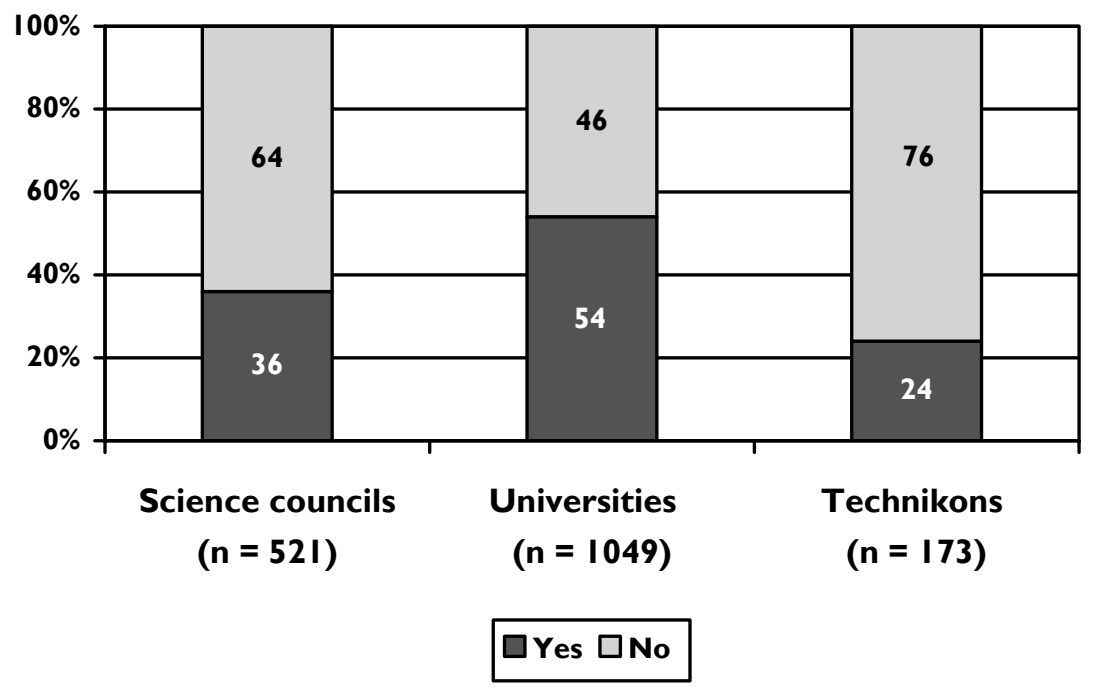

Table 3.I2 Masters and doctoral students that graduated, per sector

\begin{tabular}{|l|l|l|l|}
\hline Sector & & Masters graduates & Doctoral graduates \\
\hline Science councils & Mean & 1.86 & 1.13 \\
\hline Universities & N & 143 & 99 \\
\hline Technikons & Mean & 3.90 & 1.86 \\
\hline N & 465 & 314 \\
\hline Total & Mean & 2.57 & 1.95 \\
\hline & N & 35 & 22 \\
\hline & Mean & 3.37 & 1.70 \\
\hline & N & 643 & 435 \\
\hline
\end{tabular}

\subsubsection{Diffusion and dissemination of the project research}

Project findings may be disseminated in various ways. We asked the project leaders to indicate how they have communicated the results of their research, by selecting from 27 modes of communications, grouped together in six broad categories. The responses are summarised in Table 3.13. 
Table 3.13 Communication of research results

\begin{tabular}{|c|c|c|}
\hline Mode of communication & $\mathbf{N}$ & $\%$ \\
\hline \multicolumn{3}{|l|}{ Publications and documents } \\
\hline Articles in refereed scientific journals & 983 & 54.5 \\
\hline Published conference proceedings & 843 & 46.8 \\
\hline Contract reports & 690 & 38.3 \\
\hline Articles in popular journals & 400 & 22.2 \\
\hline Chapters in books & 274 & 15.2 \\
\hline Books/ monographs & 204 & 11.3 \\
\hline Technical manuals & 194 & 10.8 \\
\hline Written input to official policy documents & 165 & 9.2 \\
\hline Articles in refereed technical journals & 129 & 7.2 \\
\hline \multicolumn{3}{|l|}{ Presentations } \\
\hline Predominantly academic audiences & 1294 & 71.8 \\
\hline Predominantly non-academic audiences & 639 & 35.4 \\
\hline Expert committees/ panels & 452 & 25.1 \\
\hline Fairs/ exhibitions/ road shows & 203 & 11.3 \\
\hline Public hearings & 112 & 6.2 \\
\hline \multicolumn{3}{|l|}{ Patents /licenses } \\
\hline Through patenting & 78 & 4.3 \\
\hline Through licensing & 31 & 1.7 \\
\hline \multicolumn{3}{|l|}{ Training and supervision } \\
\hline Supervision of masters/ doctoral students & 593 & 32.9 \\
\hline Training through workshops & 499 & 27.7 \\
\hline Training through coursework & 384 & 21.3 \\
\hline \multicolumn{3}{|l|}{ Cooperative interactions/ informal meetings } \\
\hline Informal meetings with potential users/ teams & 713 & 39.5 \\
\hline Consultations/ technical assistance to potential users & 608 & 33.7 \\
\hline Personnel exchanges/ secondments & 329 & 18.2 \\
\hline \multicolumn{3}{|l|}{ Organisational structures } \\
\hline Through participation in consortia & 212 & 11.8 \\
\hline Through spin-off companies & 52 & 2.9 \\
\hline Through technology transfer offices & 52 & 2.9 \\
\hline Through technology incubators & 23 & 1.3 \\
\hline Through science parks & 19 & I.I \\
\hline
\end{tabular}


As can be seen in Table 3.13 the five most important modes of communication are:

$<$ Presentations to predominantly academic audiences;

$<$ Articles in refereed scientific journals;

$<$ Published conference proceedings;

$<$ Informal meetings with potential users and teams, and

$<$ Contract reports.

If we cross tabulate the modes of communication by the sector of R\&D performance (Table 3.14) then the only mode of communication that constitutes one of the top three in all the sectors is presentations to predominantly academic audiences. Contract reports as a way of dissemination are mostly of importance to the science council sector. Articles in refereed scientific journals particularly apply to the university sector.

Table 3.14 Communication of research results, per sector

\begin{tabular}{|l|l|l|l|l|l|l|}
\hline & \multicolumn{5}{l}{ Science councils Universities } & \multicolumn{3}{l}{ Technikons } \\
\hline Mode of communication & N & $\%$ & N & $\%$ & N & $\%$ \\
\hline Publications and documents & & & & & \\
\hline Articles in refereed scientific journals & 214 & 39.7 & 715 & 66.1 & 54 & 29.5 \\
\hline Articles in refereed technical journals & 54 & 10.0 & 65 & 6.0 & 10 & 5.5 \\
\hline Articles in popular journals & 158 & 29.3 & 223 & 20.6 & 19 & 10.4 \\
\hline Contract reports & 342 & 63.5 & 319 & 29.5 & 29 & 15.8 \\
\hline Books/ monographs & 43 & 8.0 & 142 & 13.1 & 19 & 10.4 \\
\hline Chapters in books & 63 & 11.7 & 196 & 18.1 & 15 & 8.2 \\
\hline Published conference proceedings & 265 & 49.2 & 495 & 45.8 & 83 & 45.4 \\
\hline Written input to official policy documents & 60 & 11.1 & 91 & 8.4 & 14 & 7.7 \\
\hline Technical manuals & 105 & 19.5 & 81 & 7.5 & 8 & 4.4 \\
\hline Presentations & & & & & & \\
\hline Academic audiences & 331 & 61.4 & 837 & 77.4 & 126 & 68.9 \\
\hline Non-academic audiences & 247 & 45.8 & 343 & 31.7 & 49 & 26.8 \\
\hline Expert committees/ panels & 191 & 35.4 & 232 & 21.5 & 29 & 15.8 \\
\hline Public hearings & 40 & 7.4 & 64 & 5.9 & 8 & 4.4 \\
\hline Fairs/ exhibitions/ road shows & 98 & 18.2 & 88 & 8.1 & 17 & 9.3 \\
\hline Patents/ licences & & & & & & \\
\hline Through patenting & 33 & 6.1 & 39 & 3.6 & 6 & 3.3 \\
\hline Through licensing & 19 & 3.5 & 12 & 1.1 & 0 & 0.0 \\
\hline
\end{tabular}


Table 3.14 Continued

\begin{tabular}{|c|c|c|c|c|c|c|}
\hline \multirow{2}{*}{ Mode of communication } & \multicolumn{2}{|c|}{ Science councils } & \multicolumn{2}{|c|}{ Universities } & \multicolumn{2}{|c|}{ Technikons } \\
\hline & $\mathbf{N}$ & $\%$ & $\mathbf{N}$ & $\%$ & $\mathbf{N}$ & $\%$ \\
\hline \multicolumn{7}{|l|}{ Training and supervision } \\
\hline Training through workshops & 162 & 30.1 & 283 & 26.2 & 54 & 29.5 \\
\hline Training through coursework & 74 & 13.7 & 275 & 25.4 & 35 & 19.1 \\
\hline Supervision of masters/ doctoral students & 86 & 16.0 & 468 & 43.3 & 40 & 21.9 \\
\hline \multicolumn{7}{|c|}{ Cooperative interactions/ informal meetings } \\
\hline $\begin{array}{l}\text { Consultations/ technical assistance to } \\
\text { potential users }\end{array}$ & 250 & 46.4 & 300 & 27.8 & 58 & 31.7 \\
\hline Personnel exchanges/ secondments & 142 & 26.3 & 160 & 14.8 & 27 & 14.8 \\
\hline Informal meetings with potential users/ teams & $28 I$ & 52.1 & 357 & 33.0 & 75 & 41.0 \\
\hline Through participation in consortia & 112 & 20.8 & 87 & 8.0 & 13 & 7.1 \\
\hline Through science parks & 6 & I.I & 13 & 1.2 & 37 & 20.2 \\
\hline Through spin-off companies & 21 & 3.9 & 30 & 2.8 & $\mathbf{I}$ & 0.5 \\
\hline Through technology transfer offices & 36 & 6.7 & 15 & 1.4 & $\mathbf{I}$ & 0.5 \\
\hline Through technology incubators & 12 & 2.2 & 9 & 0.8 & 2 & I.I \\
\hline
\end{tabular}

\subsection{Determinants of research utilisation: the results of bivariate analyses}

In this section we look at the relationship between research utilisation and various aspects of the project. This involves a series of cross tabulations, with the question "Did the intended beneficiaries recognise/ utilise/ implement the research as planned?" as constant in all contingency tables. The results of the cross tabulations are displayed in Sections 3.3.I to 3.3.8.

\subsubsection{Sector of R\&D performance}

The sector of R\&D performance, as measured by the institutional affiliation of the project leader, was the first variable to be cross-tabulated by the extent of research utilisation. Table 3.I5 shows that science councils have the greatest extent of research utilisation, and technikons the lowest. 
Table 3.15 Cross tabulation between research utilisation and the institutional classification of the project leader

\begin{tabular}{|c|c|c|c|c|c|}
\hline \multirow{2}{*}{$\begin{array}{l}\text { Institutional } \\
\text { classification }\end{array}$} & \multicolumn{4}{|c|}{$\begin{array}{l}\text { Did the intended beneficiaries recognise/ utilise/ } \\
\text { implement the research as planned? }\end{array}$} & \multirow{2}{*}{$\begin{array}{l}\text { Number of } \\
\text { projects }\end{array}$} \\
\hline & $\begin{array}{l}\text { Yes, to some } \\
\text { extent }\end{array}$ & $\begin{array}{l}\text { Yes, to little } \\
\text { extent }\end{array}$ & No, not at all & Don't know & \\
\hline Science councils & 63.7 & 16.7 & 8.3 & 11.3 & 529 \\
\hline Universities & 55.4 & 16.5 & 6.9 & 21.2 & 1050 \\
\hline Technikons & 45.9 & 18.8 & 13.5 & 21.8 & 170 \\
\hline
\end{tabular}

\subsubsection{Motive or reason for the research}

The second variable to consider as determinant of research utilisation was the motive or reason for the research (Table 3.16). Research utilisation is highest where the research has been conducted in response to an external request (a tender or contract from an outside company or funding agency). Also, greater uncertainty exists about the project's eventual utilisation in cases where the research was born out of own curiosity or interest.

Table 3.16 Cross tabulation between research utilisation and the motive or reason for the research

\begin{tabular}{|c|c|c|c|c|c|}
\hline \multirow{2}{*}{$\begin{array}{l}\text { What triggered the } \\
\text { research? }\end{array}$} & \multicolumn{4}{|c|}{$\begin{array}{l}\text { Did the intended beneficiaries recognise/ } \\
\text { utilise/ implement the research as planned? }\end{array}$} & \multirow{2}{*}{$\begin{array}{l}\text { Number } \\
\text { of } \\
\text { projects }\end{array}$} \\
\hline & $\begin{array}{l}\text { Yes, to } \\
\text { some extent }\end{array}$ & $\begin{array}{l}\text { Yes, to } \\
\text { little extent }\end{array}$ & $\begin{array}{l}\text { No, not } \\
\text { at all }\end{array}$ & Don't know & \\
\hline $\begin{array}{l}\text { An outside firm / company / } \\
\text { institution approaching you }\end{array}$ & 74.4 & 11.4 & 5.8 & 8.4 & 359 \\
\hline A tender / contract research & 74.0 & 12.2 & 5.5 & 8.3 & 181 \\
\hline $\begin{array}{l}\text { A funding agency requesting } \\
\text { proposals }\end{array}$ & 68.5 & 14.7 & 4.9 & 12.0 & 184 \\
\hline Previous research by yourself & 62.0 & 15.8 & 5.9 & 16.2 & 727 \\
\hline $\begin{array}{l}\text { Colleague(s) approaching you to } \\
\text { form part of a team }\end{array}$ & 60.9 & 14.4 & 8.4 & 16.3 & 417 \\
\hline $\begin{array}{l}\text { Own interpretation of the } \\
\text { immediate / future environment }\end{array}$ & 59.7 & 21.2 & 6.7 & 12.4 & 466 \\
\hline $\begin{array}{l}\text { Own curiosity or research } \\
\text { interest }\end{array}$ & 53.6 & 17.5 & 8.5 & 20.4 & 858 \\
\hline
\end{tabular}

The general trend in Table 3.16 is clear and relates to the continuum of types of R\&D, i.e. applied, strategic and fundamental research. Applied or application driven research, being short-term, is more likely to be utilised by the intended beneficiaries than fundamental research, which is mostly long-term. (Figure 3.5). 
Figure 3.5 The relationship between types of $R \& D$ and research utilisation

* An outside firm / company / institution approaching you

* A tender / contract research
* A funding agency requesting proposals

* Previous research by yourself

* Colleague(s) approaching you to form part of a team

* Own interpretation of the immediate / future environment

\section{Applied}

* Immediate / shortterm

* Solutions driven

\section{Strategic}

* $\quad$ Medium-term
* Own curiosity or research interest

Fundamental

* Long-term

* Curiosity driven

\subsubsection{Broad research domain}

As far as broad research domain is concerned, Table 3.17 shows that projects within the agricultural, environmental, engineering and biological sciences are more likely to be utilised. Against this, projects within arts and humanities, economic and management sciences, as well as the social and mathematical sciences, have the smallest probability of being utilised to some extent.

Table 3.I7 Cross tabulation between research utilisation and broad research domain

\begin{tabular}{|l|l|l|l|l|l|l|}
\hline Broad research domain & \multicolumn{3}{l}{$\begin{array}{l}\text { Did the intended beneficiaries recognise I } \\
\text { utilisel implement the research as planned? }\end{array}$} & $\begin{array}{l}\text { Number of } \\
\text { projects }\end{array}$ \\
\hline & $\begin{array}{l}\text { Yes, to some } \\
\text { extent }\end{array}$ & $\begin{array}{l}\text { Yes, to little No, not } \\
\text { extent }\end{array}$ & $\begin{array}{l}\text { Don't } \\
\text { at all } \\
\text { know }\end{array}$ & \\
\hline Agricultural sciences & 69.3 & 13.2 & 5.8 & II.7 & 326 \\
\hline Environmental sciences & 66.2 & 12.9 & 8.3 & 12.6 & 278 \\
\hline Engineering sciences & 64.8 & 12.2 & 11.7 & 11.3 & 213 \\
\hline Biological sciences & 64.6 & 15.8 & 6.7 & 12.8 & 297 \\
\hline Medical sciences: clinical & 64.1 & 9.4 & 4.7 & 21.9 & 64 \\
\hline Earth sciences & 63.6 & 19.7 & 5.3 & 11.4 & 132 \\
\hline Physical sciences & 63. & 7.9 & 7.9 & 21.1 & 76 \\
\hline $\begin{array}{l}\text { Applied science and } \\
\text { technologies }\end{array}$ & 60.6 & 16.2 & 12.4 & 10.9 & 340 \\
\hline $\begin{array}{l}\text { Information and } \\
\text { communication technologies }\end{array}$ & 59.6 & 16.3 & 12.1 & 12.1 & 141 \\
\hline & & & & & \\
\hline
\end{tabular}


Table 3.17 Continued

\begin{tabular}{|l|l|l|l|l|l|}
\hline Broad research domain & \multicolumn{3}{l}{$\begin{array}{l}\text { Did the intended beneficiaries recognise I } \\
\text { utilise/ implement the research as planned? }\end{array}$} & $\begin{array}{l}\text { Number of } \\
\text { projects }\end{array}$ \\
\hline $\begin{array}{l}\text { Yes, to some } \\
\text { extent }\end{array}$ & $\begin{array}{l}\text { Yes, to little No, not } \\
\text { extent }\end{array}$ & $\begin{array}{l}\text { Don't } \\
\text { at all }\end{array}$ & know \\
\hline Medical sciences: basic & 58.7 & 15.2 & 6.5 & 19.6 & 92 \\
\hline Chemical sciences & 58.5 & 13.0 & 12.2 & 16.3 & 123 \\
\hline Marine sciences & 56.8 & 21.6 & 8.1 & 13.5 & 37 \\
\hline Health sciences & 56.6 & 17.2 & 8.1 & 18.2 & 297 \\
\hline Material sciences & 56.0 & 18.7 & 12.0 & 13.3 & 75 \\
\hline Arts and humanities & 53.2 & 18.9 & 5.7 & 22.2 & 333 \\
\hline Economic and management & 53.1 & 20.6 & 7.0 & 19.3 & 243 \\
\hline sciences & & & & & \\
\hline Social sciences & 52.9 & 21.9 & 8.3 & 16.9 & 433 \\
\hline Mathematical sciences & 52.3 & 17.4 & 5.8 & 24.4 & 86 \\
\hline
\end{tabular}

A possible explanation for the trend in Table 3.17 is that projects in the mathematical and socially oriented sciences are generally more likely to be triggered by own curiosity or research interest (Table 3.18).

Table 3.18 Cross tabulation between selected research domains and motive or reason for the utilisation of research

\begin{tabular}{|l|l|l|l|l|}
\hline Research domain & $\begin{array}{l}\text { What triggered the research? } \\
\text { An outside firm/ } \\
\text { company/ institution } \\
\text { approaching you (A) }\end{array}$ & $\begin{array}{l}\text { Own curiosity or } \\
\text { research interest } \\
\text { (B) }\end{array}$ & $\begin{array}{l}\text { A and } \\
\text { B }\end{array}$ & Not A or B \\
\hline Greater utilisation & 23.1 & 28.3 & 9.4 & 39.2 \\
\hline Agricultural & 19.6 & 37.7 & 7.8 & 34.9 \\
\hline Environmental & 27.2 & 27.6 & 8.8 & 36.4 \\
\hline Engineering & 19.7 & 39.0 & 9.0 & 32.3 \\
\hline Biological & & & 4.9 & 29.0 \\
\hline Lesser utilisation & 5.8 & 60.3 & 4.4 & 31.6 \\
\hline Arts \& humanities & 5.8 & 50.8 & & \\
\hline $\begin{array}{l}\text { Economic \& } \\
\text { management }\end{array}$ & 13.2 & 51.0 & 5.4 & 31.4 \\
\hline Social & 12.2 & 42.7 & 5.6 & 38.2 \\
\hline Mathematical & 13.5 & & & \\
\hline
\end{tabular}




\subsubsection{Research experience of project leader}

The variable that measures the research experience of the project leaders was dichotomised by using the median years of experience within each sector as demarcation. Thus, for the science council sector the cut-off point were 13 years, and for universities and technikons 12 and 5 years respectively (see Table 3.2). The cross tabulation of research utilisation by years of research experience is shown in Figure 3.6.

Figure 3.6 Cross tabulation between research utilisation and years of research experience

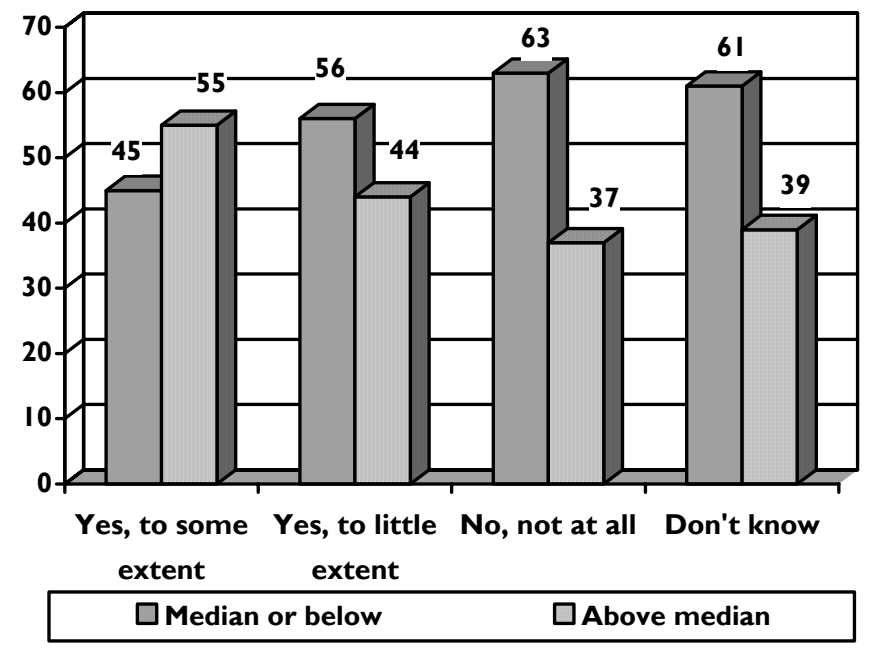

In Figure 3.6 the research experience of the project leader is positively related to the utilisation of the project research: the greater the experience of the researcher, the greater the likelihood of eventual utilisation.

\subsubsection{Time devoted to the project}

We asked the project leaders approximately how much of their total working time they had devoted to the project during the course of the project (scale ranged from $10 \%$ to $100 \%$ ). Cross tabulating their responses by research utilisation, the figures in Table 3.19 are derived. 
Table 3.19 Cross tabulation between research utilisation and time spent on the project

\begin{tabular}{|c|c|c|c|c|c|}
\hline \multirow{2}{*}{$\begin{array}{l}\text { Time spent on } \\
\text { project }\end{array}$} & \multicolumn{4}{|c|}{$\begin{array}{l}\text { Did the intended beneficiaries recognise/ utilise/ } \\
\text { implement the research as planned? }\end{array}$} & \multirow{2}{*}{$\begin{array}{l}\text { Number of } \\
\text { projects }\end{array}$} \\
\hline & $\begin{array}{l}\text { Yes, to some } \\
\text { extent }\end{array}$ & $\begin{array}{l}\text { Yes, to little } \\
\text { extent }\end{array}$ & $\begin{array}{l}\text { No, not at } \\
\text { all }\end{array}$ & Don't know & \\
\hline \multicolumn{6}{|l|}{ Universities } \\
\hline $10-20 \%$ & 54.3 & 15.2 & 6.7 & 23.8 & 466 \\
\hline $30-40 \%$ & 56.2 & 20.3 & 6.1 & 17.4 & 345 \\
\hline $50 \%+$ & 56.8 & 13.1 & 8.5 & 21.6 & 236 \\
\hline \multicolumn{6}{|l|}{ Technikons } \\
\hline $10-20 \%$ & 43.1 & 19.4 & 13.9 & 23.6 & 72 \\
\hline $30-40 \%$ & 44.8 & 20.9 & 16.4 & 17.9 & 67 \\
\hline $50 \%+$ & 56.7 & 10.0 & 6.7 & 26.7 & 30 \\
\hline \multicolumn{6}{|l|}{ Science councils } \\
\hline $10-20 \%$ & 69.3 & 13.6 & 4.5 & 12.5 & 88 \\
\hline $30-40 \%$ & 64.4 & 15.6 & 7.4 & 12.6 & 135 \\
\hline $50 \%+$ & 62.7 & 17.7 & 9.3 & 10.3 & 300 \\
\hline
\end{tabular}

The amount of time spent on the project has its largest impact within the technikon sector: utilisation ("yes, to some extent") improves from $43 \%$ to $57 \%$ as time devoted to the project increases. Moreover, in the science council sector there is the interesting trend of declining utilisation as time spent on the project increases (from 69\% to 63\%).

\subsubsection{Size of project funding}

Size of project funding has emerged as a strong determinant of research utilisation, as is evident in Table 3.20. The general trend is that the higher the category of funding, the greater the possibility of the research being utilised to some extent. Similarly, smaller categories of funding are associated with greater uncertainty about the utilisation of the research. 
Table 3.20 Cross tabulation between research utilisation and project funding

\begin{tabular}{|c|c|c|c|c|c|}
\hline \multirow{2}{*}{ Funding } & \multicolumn{4}{|c|}{$\begin{array}{l}\text { Did the intended beneficiaries recognise/ utilise/ } \\
\text { implement the research as planned? }\end{array}$} & \multirow{2}{*}{$\begin{array}{l}\text { Number of } \\
\text { projects }\end{array}$} \\
\hline & $\begin{array}{l}\text { Yes, to some } \\
\text { extent }\end{array}$ & $\begin{array}{l}\text { Yes, to little } \\
\text { extent }\end{array}$ & $\begin{array}{l}\text { No, not } \\
\text { at all }\end{array}$ & Don't know & \\
\hline \multicolumn{6}{|l|}{ Higher education } \\
\hline Less than R50 000 & 44.0 & 20.9 & 9.0 & 26.2 & 657 \\
\hline R50 000 - R249 000 & 63.8 & 13.0 & 7.2 & 15.9 & 276 \\
\hline R250 000 or more & 74.9 & 12.8 & 5.2 & 7.1 & 211 \\
\hline \multicolumn{6}{|c|}{ Science council sector } \\
\hline Less than R250 000 & 58.3 & 16.2 & 7.9 & 17.6 & 216 \\
\hline R250 000 - R999000 & 65.1 & 18.6 & 9.3 & 7.0 & 172 \\
\hline RI 000000 or more & 70.8 & I5.4 & 6.5 & 7.3 & 123 \\
\hline
\end{tabular}

\subsubsection{Project collaboration}

Collaboration with others on the project is another strong determinant of the extent of research utilisation. If collaboration is present, the probability of a research project being utilised to some extent improves, on average, by about $23 \%$. The largest impact of collaboration (28\%) is recorded for the technikon sector (from $27.3 \%$ to $55.3 \%$ ).

Table 3.2I Cross tabulation between research utilisation and collaboration on the project

\begin{tabular}{|c|c|c|c|c|c|}
\hline \multirow{2}{*}{ Collaboration } & \multicolumn{4}{|c|}{$\begin{array}{l}\text { Did the intended beneficiaries recognise/ utilise/ } \\
\text { implement the research as planned? }\end{array}$} & \multirow{2}{*}{$\begin{array}{l}\text { Number of } \\
\text { projects }\end{array}$} \\
\hline & $\begin{array}{l}\text { Yes, to some } \\
\text { extent }\end{array}$ & $\begin{array}{l}\text { Yes, to little } \\
\text { extent }\end{array}$ & $\begin{array}{l}\text { No, not } \\
\text { at all }\end{array}$ & $\begin{array}{l}\text { Don't } \\
\text { know }\end{array}$ & \\
\hline \multicolumn{6}{|l|}{ All sectors } \\
\hline Yes & 62.5 & 16.0 & 6.3 & 15.2 & 1320 \\
\hline No & 39.6 & 19.2 & 13.0 & 28.3 & 407 \\
\hline
\end{tabular}

Science councils

\begin{tabular}{|l|l|l|l|l|l|}
\hline Yes & 66.5 & 17.0 & 6.6 & 9.9 & 454 \\
\hline No & 47.0 & 12.1 & 18.2 & 22.7 & 66 \\
\hline Universities & & & & & \\
\hline Yes & 61.2 & 15.0 & 5.6 & 18.2 & 752 \\
\hline No & 40.2 & 20.6 & 10.1 & 29.0 & 286 \\
\hline Technikons & & & & & \\
\hline Yes & 55.3 & 18.4 & 9.6 & 16.7 & 114 \\
\hline No & 27.3 & 20.0 & 21.8 & 30.9 & 55 \\
\hline
\end{tabular}




\subsubsection{Intended beneficiaries of the research}

The cross tabulation of research utilisation by the nature of the intended beneficiaries appears in Table 3.22. Research utilisation appears greater when the beneficiary is an entity with clear organisational boundaries, such as a specific agency, interest group or firm. This also implies that research utilisation is highest when the research is commissioned and there is a clear research contract.

Table 3.22 Cross tabulation between research utilisation and the intended beneficiaries of the project

\begin{tabular}{|c|c|c|c|c|c|}
\hline \multirow[b]{2}{*}{ Intended beneficiaries } & \multicolumn{4}{|c|}{$\begin{array}{l}\text { Did the intended beneficiaries recognise/ utilise/ } \\
\text { implement the research as planned? }\end{array}$} & \multirow{2}{*}{$\begin{array}{l}\text { Number of } \\
\text { projects }\end{array}$} \\
\hline & $\begin{array}{l}\text { Yes, to some } \\
\text { extent }\end{array}$ & $\begin{array}{l}\text { Yes, to } \\
\text { little } \\
\text { extent }\end{array}$ & $\begin{array}{l}\text { No, } \\
\text { not at } \\
\text { all }\end{array}$ & $\begin{array}{l}\text { Don't } \\
\text { know }\end{array}$ & \\
\hline The contracting agency & 69.8 & I5.3 & 5.2 & 9.7 & 268 \\
\hline Specific interest groups & 62.6 & 16.1 & 6.1 & 15.2 & 521 \\
\hline Industry/ firms & 60.5 & 16.1 & 10.2 & 13.2 & 539 \\
\hline $\begin{array}{l}\text { General public/ society/ } \\
\text { community }\end{array}$ & 57.4 & 17.4 & 7.2 & 18.0 & 545 \\
\hline Government & 55.8 & 18.5 & 8.3 & I7.5 & 504 \\
\hline $\begin{array}{l}\text { Colleagues/ scholars/ peers: } \\
\text { other disciplines }\end{array}$ & 55.1 & 19.2 & 6.1 & 19.6 & 459 \\
\hline $\begin{array}{l}\text { Colleagues/scholars/ peers: } \\
\text { own discipline }\end{array}$ & 54.9 & 18.4 & 5.8 & 20.9 & 1064 \\
\hline
\end{tabular}

\subsection{Determinants of research utilisation: the results of multivariate analyses}

In this section "research utilisation" was specified as a dependent variable and, together with a set of independent variables, submitted to a CHAID procedure. The purpose of CHAID (Chi-squared Automatic Interaction Detector) is to construct trees where each node identifies a split condition, to yield optimum classification for the categorical dependent variable. Differently put, CHAID visually displays models from which one can identify those groups that matter in the classification of research utilisation.

Three sets of CHAID analyses were performed: one for the higher education and science council sectors combined, and one for each sector on its own. 


\subsubsection{Science council and higher education sectors combined}

For the combined analysis of CHAID the input variables were as follows:

\section{Dependent variable}

- Did the intended beneficiaries recognise/ utilise/ implement the research as planned? ( $I$ = Yes, to some extent; 2 = Yes, to little extent; 3 = No, not at all; 4 = Don't know)

\section{Independent variables}

- Institution ( 1 = Science councils; 2 = Universities; 3 = Technikons)

- How long have you been involved in research? ( 1 = Median or below; 2 = Above median)

- Science culture of project activities ( $I$ = Social sciences; 2 = Natural sciences; $3=$ Health \& medical sciences; $4=$ Interdisciplinary social sciences; $5=$ Natural and health $\&$ medical sciences combined)

- Did you collaborate with others on the project? $(I=$ Yes; 2 = No)

- Approximately how much of your total working time did you devote to this project during the course of the project? $(I=10-20 \% ; 2=30-40 \% ; 3=50 \%+)$

Figure 3.7 summarises the outcome of the CHAID analysis. 

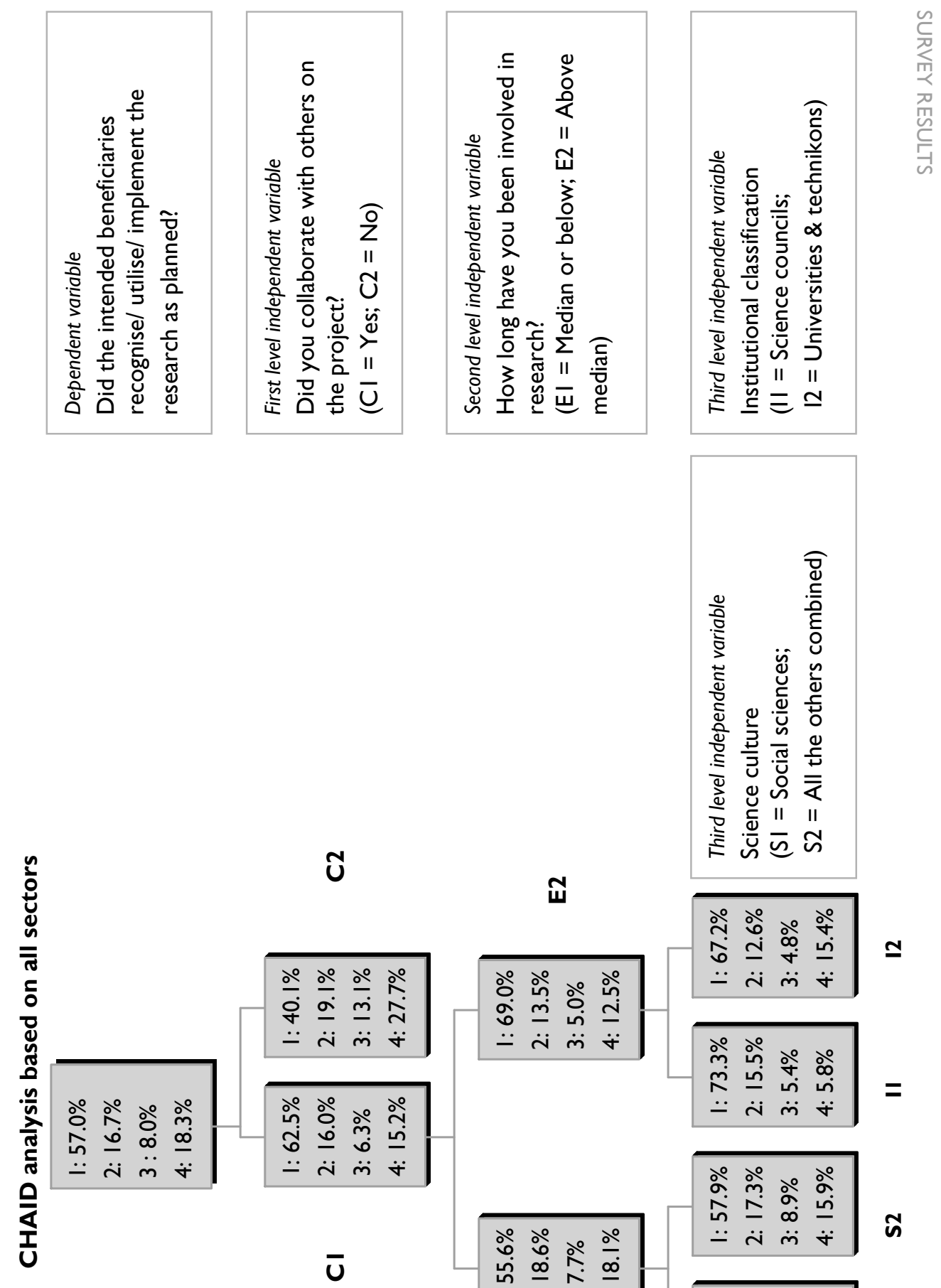

m
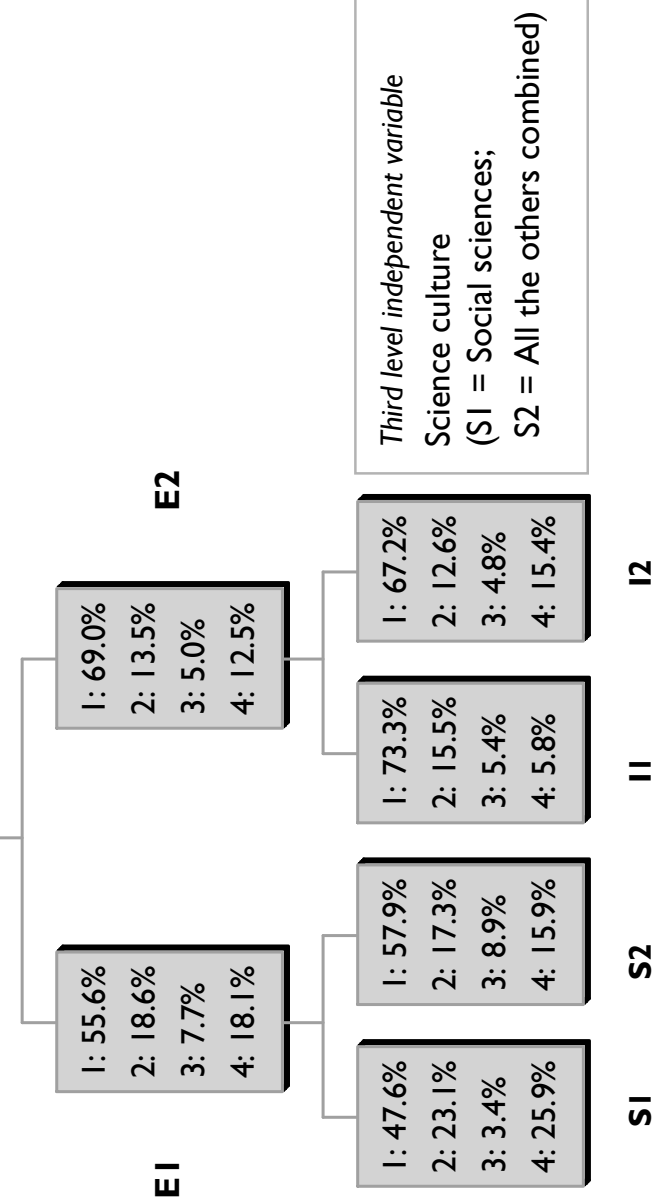
As can be seen in Figure 3.7, collaboration is the single most important determinant of research utilisation: $62.5 \%$ of all projects with collaboration have been recognised/ utilised/ implemented to some extent by the intended beneficiaries, compared to $40.1 \%$ of projects with no collaboration.

The second most important predictor is the research experience of the project leader. The percentage of projects utilised to some extent drops from $62.5 \%$ to $55.6 \%$ if the project leader has less than the median years of research experience. If the project leader has more than the median years of experience, utilisation improves to $69 \%$.

Two independent variables feature on the third level of the CHAID outcome. The first, the science culture classification of the project activities, impacts only on cases where there is collaboration and the project leader has limited research experience. Under these circumstances, research utilisation will drop from $55.6 \%$ to $47.6 \%$ if the collaboration is within the social sciences only. The second independent variable on this level relates to projects where there is collaboration and the research project leader has significant research experience. Here research utilisation will improve from $69 \%$ to $73.3 \%$ if the project is housed at a science council.

The result of the CHAID was further explored through various cross tabulations, especially with institutional classification, sector of collaboration and the science culture of the project. These breakdowns are only for projects that have been utilised to some extent.

Table 3.23 Breakdown by institutional classification and sector of collaboration (projects with collaboration)

\begin{tabular}{|c|c|c|c|c|c|c|}
\hline \multirow{2}{*}{ Collaborated with } & \multicolumn{2}{|c|}{ Higher Education sector } & \multicolumn{2}{|c|}{ Science council sector } & \multicolumn{2}{|c|}{ Total } \\
\hline & $\%$ & $\mathbf{N}$ & $\%$ & $\mathbf{N}$ & $\%$ & $\mathbf{N}$ \\
\hline NGOs & 77.0 & 87 & 73.9 & 69 & 75.6 & 156 \\
\hline Industry/ business & 70.0 & 200 & 68.9 & 206 & 69.5 & 406 \\
\hline Science council(s) & 65.4 & 52 & 69.9 & 176 & 68.9 & 228 \\
\hline Government & 64.2 & 137 & 68.6 & 140 & 66.4 & 277 \\
\hline Academics/ scholars & 60.6 & 749 & 68.0 & 294 & 62.7 & 1043 \\
\hline
\end{tabular}

The breakdown of utilisation (operationalised by the response "Yes - to some extent") by sector of collaboration shows that projects with an NGO as collaborator are more likely to be utilised. Of I 56 projects with an NGO as collaborator almost $76 \%$ of projects have been utilised to some extent by the intended beneficiaries.

Research projects involving collaboration with industry/business have the second highest likelihood of utilisation in the higher education sector (70\%). In the science council sector, collaboration with other science councils assumes the second place (69.9\%). 
Table 3.24 gives a further breakdown of Table 3.23, by also incorporating years of research experience (above or below the median - see Section 3.2.3).

Table 3.24 Breakdown by institutional classification and years involved in research (projects with collaboration, per sector of collaboration)

\begin{tabular}{|c|c|c|c|c|c|c|}
\hline \multirow{2}{*}{$\begin{array}{l}\text { Years involved in } \\
\text { research }\end{array}$} & \multicolumn{2}{|c|}{ Higher Education sector } & \multicolumn{2}{|c|}{ Science council sector } & \multicolumn{2}{|c|}{ Total } \\
\hline & $\%$ & $\mathrm{~N}$ & $\%$ & $\mathrm{~N}$ & $\%$ & $\mathrm{~N}$ \\
\hline \multicolumn{7}{|l|}{ Academics/ scholars } \\
\hline Median or below & 53.2 & 344 & 62.3 & 162 & 56.1 & 506 \\
\hline Above median & 66.8 & 400 & 75.8 & 128 & 68.9 & 528 \\
\hline \multicolumn{7}{|l|}{ Government } \\
\hline Median or below & 61.1 & 54 & 66.7 & 75 & 64.3 & 129 \\
\hline Above median & 66.3 & 83 & 70.8 & 65 & 68.2 & 148 \\
\hline \multicolumn{7}{|l|}{ Science council(s) } \\
\hline Median or below & 58.8 & 17 & 63.6 & 88 & 62.9 & 105 \\
\hline Above median & 68.6 & 35 & 76.1 & 88 & 74.0 & 123 \\
\hline \multicolumn{7}{|l|}{ NGOs } \\
\hline Median or below & 62.2 & 37 & 70.7 & 41 & 66.7 & 78 \\
\hline Above median & 88.0 & 50 & 78.6 & 28 & 84.6 & 78 \\
\hline \multicolumn{7}{|l|}{ Industry/ business } \\
\hline Median or below & 57.3 & 75 & 61.2 & 116 & 59.7 & 191 \\
\hline Above median & 77.6 & 125 & 78.7 & 89 & 78.0 & 214 \\
\hline
\end{tabular}

The research experience of the primary researcher is crucial for utilisation, especially when collaborating with NGOs and industry/business, and even more so when the primary researcher is employed within higher education. For instance, if the project leader's research experience is less than that of the median for his/her sector, only $62.2 \%$ of HES projects with collaboration in the NGO sector seem to be utilised to some extent. This increases drastically to $88 \%$ for researchers with above average research experience.

Tables 3.25 and 3.26 differ from Tables 3.23 and 3.24 in that the sector of collaboration has been replaced by the science culture of the project activities. 
Table 3.25 Breakdown by institutional classification and science culture (projects with collaboration)

\begin{tabular}{|c|c|c|c|c|c|c|}
\hline \multirow{2}{*}{ Science culture } & \multicolumn{2}{|c|}{ Higher Education sector } & \multicolumn{2}{|c|}{ Science council sector } & \multicolumn{2}{|c|}{ Total } \\
\hline & $\%$ & $\mathbf{N}$ & $\%$ & $\mathbf{N}$ & $\%$ & $\mathbf{N}$ \\
\hline $\begin{array}{l}\text { Interdisciplinary } \\
\text { social sciences }\end{array}$ & 64.9 & $|3|$ & 68.1 & 72 & 66.0 & 203 \\
\hline $\begin{array}{l}\text { Natural and health \& } \\
\text { medical sciences }\end{array}$ & 64.4 & 59 & 68.8 & 32 & 65.9 & 91 \\
\hline Natural sciences & 63.1 & 295 & 66.8 & 310 & 65.0 & 605 \\
\hline Social sciences & 56.9 & 283 & 59.1 & 22 & 57.0 & 305 \\
\hline $\begin{array}{l}\text { Health \& medical } \\
\text { sciences }\end{array}$ & 53.1 & 96 & 64.7 & 17 & 54.9 & 113 \\
\hline
\end{tabular}

Projects of a more interdisciplinary nature (interdisciplinary social sciences, and a combination of natural and health and medical sciences) are more likely to be utilised than those associated with a single science culture (especially social sciences). This applies to both higher education and science council projects (Table 3.25).

Table 3.26 Breakdown by institutional classification and years involved in research (projects with collaboration, per science culture)

\begin{tabular}{|c|c|c|c|c|c|c|}
\hline \multirow{2}{*}{ Science culture } & \multicolumn{2}{|c|}{ Higher Education sector } & \multicolumn{2}{|c|}{ Science council sector } & \multicolumn{2}{|c|}{ Total } \\
\hline & $\%$ & $\mathbf{N}$ & $\%$ & $\mathbf{N}$ & $\%$ & $\mathbf{N}$ \\
\hline \multicolumn{7}{|l|}{ Social sciences } \\
\hline Median or below & 48.1 & 135 & 41.7 & 12 & 47.6 & 147 \\
\hline Above median & 64.9 & 148 & 80.0 & 10 & 65.8 & 158 \\
\hline \multicolumn{7}{|l|}{ Natural sciences } \\
\hline Median or below & 57.1 & 126 & 61.7 & 167 & 59.7 & 293 \\
\hline Above median & 66.9 & 166 & 73.6 & 140 & 69.9 & 306 \\
\hline \multicolumn{7}{|c|}{ Health \& medical sciences } \\
\hline Median or below & 48.0 & 50 & 60.0 & 10 & 50.0 & 60 \\
\hline Above median & 57.8 & 45 & 71.4 & 7 & 59.6 & 52 \\
\hline \multicolumn{7}{|c|}{ Interdisciplinary social sciences } \\
\hline Median or below & 57.1 & 63 & 64.3 & 42 & 60.0 & 105 \\
\hline Above median & 73.1 & 67 & 72.4 & 29 & 72.9 & 96 \\
\hline \multicolumn{7}{|c|}{ Natural and health \& medical sciences } \\
\hline Median or below & 41.2 & 17 & 62.5 & 16 & 51.5 & 33 \\
\hline Above median & 73.8 & 42 & 75.0 & 16 & 74.1 & 58 \\
\hline
\end{tabular}

In Table 3.26 the research experience of the primary researcher makes the largest difference in the utilisation of (a) projects in the social sciences within the science council 
sector (utilisation increased from $41.7 \%$ to $80 \%$ ) and (b) interdisciplinary projects in the natural and medical and health sciences within the higher education sector (utilisation increased from $41.2 \%$ to $73.8 \%$ ). These findings, however, should be interpreted with circumspection, given the small number of projects on which the observations are based.

\subsubsection{Science council sector}

The following variables served as input to the CHAID analysis for the science council sector:

\section{Dependent variable}

- Did the intended beneficiaries recognise/ utilise/ implement the research as planned? ( $I=$ Yes, to some extent; 2 = Yes, to little extent; $3=$ No, not at all; 4 = Don't know $)$

\section{Independent variables}

- How long have you been involved in research? (I = Median or below; 2 = Above median)

- Science culture of project activities $(I=$ Social sciences; $2=$ Natural sciences; $3=$ Health \& medical sciences; 4 = Interdisciplinary social sciences; $5=$ Natural and health \& medical sciences)

- How much funding did you have for the project in total? ( $I$ = Less than R250 000; 2 = R250 000 to R999 000; 3 = RI 000000 or more)

- Did you collaborate with others on the project? ( $\mathrm{I}=$ Yes; 2 = No)

- Approximately how much of your total working time did you devote to this project during the course of the project? ( $I=10-20 \% ; 2=30-40 \% ; 3=50 \%+)$

The outcome of the CHAID analysis for science councils is shown in Figure 3.8. This almost replicates that of the combined analysis (Figure 3.7) as far as the first two levels of independent variables are concerned. Again collaboration seems to be the most important predictor of research utilisation, followed by the research experience of the project leader (66.1\% of projects with collaboration have been utilised to some extent by the intended beneficiaries, which increases to $73.6 \%$ if the project leader's research experience surpasses the median for his/her sector of employment). 

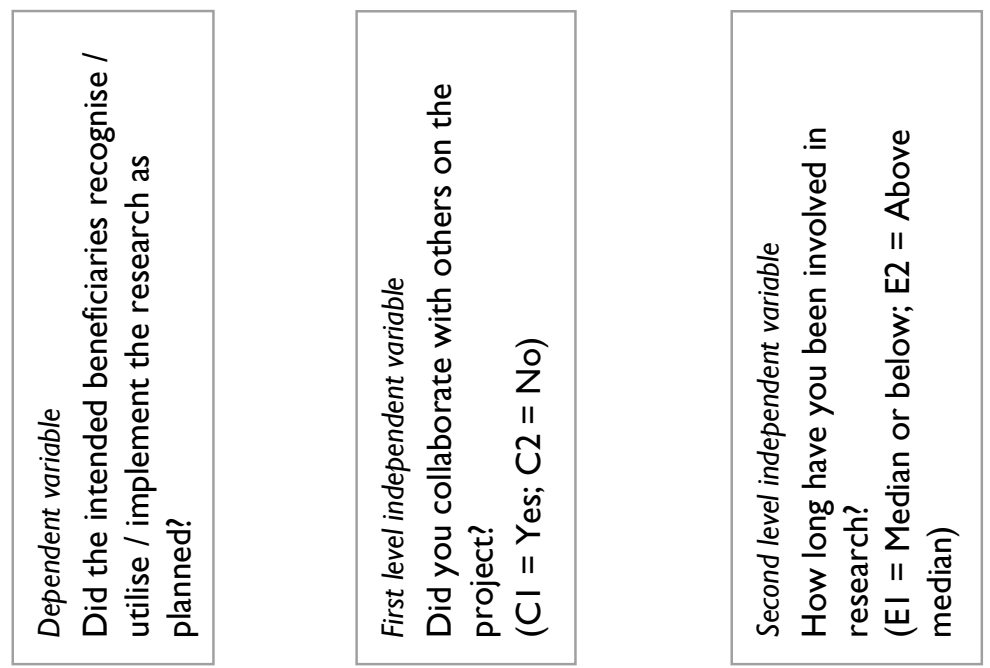

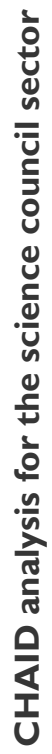

ช
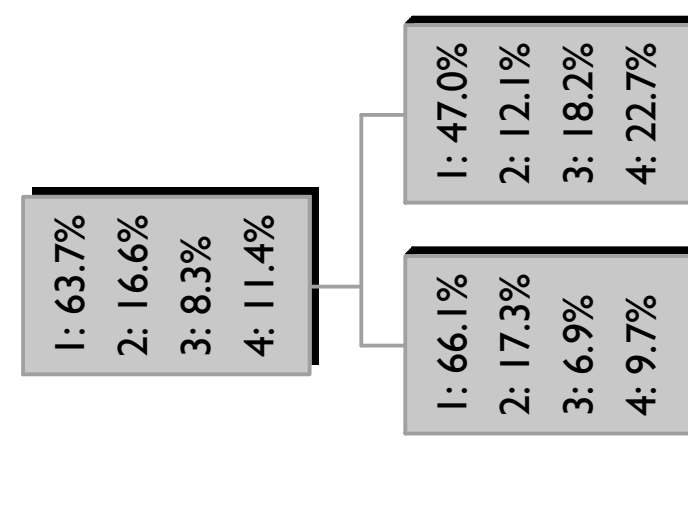

บี

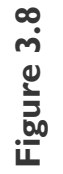


Table 3.27 gives a breakdown of science council projects by sector of collaboration and years of research experience, based on the number of projects that have been utilised to some extent.

Table 3.27 Breakdown by sector of collaboration and years of experience (science council projects with collaboration)

\begin{tabular}{|c|c|c|c|c|c|c|}
\hline \multirow[t]{2}{*}{ Collaborated with } & \multicolumn{2}{|c|}{$\begin{array}{l}\text { Research experience } \\
\text { Median or below }\end{array}$} & \multicolumn{2}{|c|}{$\begin{array}{l}\text { Research experience } \\
\text { Above the median }\end{array}$} & \multicolumn{2}{|c|}{ Total } \\
\hline & $\%$ & $\mathbf{N}$ & $\%$ & $\mathbf{N}$ & $\%$ & $\mathbf{N}$ \\
\hline NGOs & 70.7 & 41 & 78.6 & 28 & 73.9 & 69 \\
\hline Science council(s) & 63.6 & 88 & 76.1 & 88 & 69.9 & 176 \\
\hline Industry/ business & 61.2 & 116 & 78.7 & 89 & 68.9 & 206 \\
\hline Government & 66.7 & 75 & 70.8 & 65 & 68.6 & 140 \\
\hline Academics/ scholars & 62.3 & 162 & 75.8 & 128 & 68.0 & 294 \\
\hline
\end{tabular}

For more experienced researchers, projects conducted in collaboration with government are less likely to be utilised $(70.8 \%)$ compared to projects conducted in collaboration with industry/business (78.7\%) and NGOs (78.6\%). For less experienced researchers, projects conducted in collaboration with NGOs have the best chance of being utilised $(70.7 \%)$.

\subsubsection{Higher education sector}

The input variables for the CHAID analysis based on the higher education data are as follows:

\section{Dependent variable}

- Did the intended beneficiaries recognise/ utilise/ implement the research as planned? ( $I$ = Yes, to some extent; 2 = Yes, to little extent; 3 = No, not at all; 4 = Don't know)

\section{Independent variables}

- How long have you been involved in research? ( $\mathrm{I}=$ Median or below; 2 = Above median)

- Science culture of project activities ( $I=$ Social sciences; $2=$ Natural sciences; $3=$ Health \& medical sciences; 4 = Interdisciplinary social sciences; 5 = Natural and health \& medical sciences)

- How much funding did you have for the project in total? ( $I$ = Less than R50 000; 2 = R50 000 to R249 000; 3 = R500 000 or more)

- Did you collaborate with others on the project? $(I=$ Yes; $2=\mathrm{No})$

- Approximately how much of your total working time did you devote to this project during the course of the project? $(I=10-20 \% ; 2=30-40 \% ; 3=50 \%+)$

The outcome of the CHAID appears in Figure 3.9. 

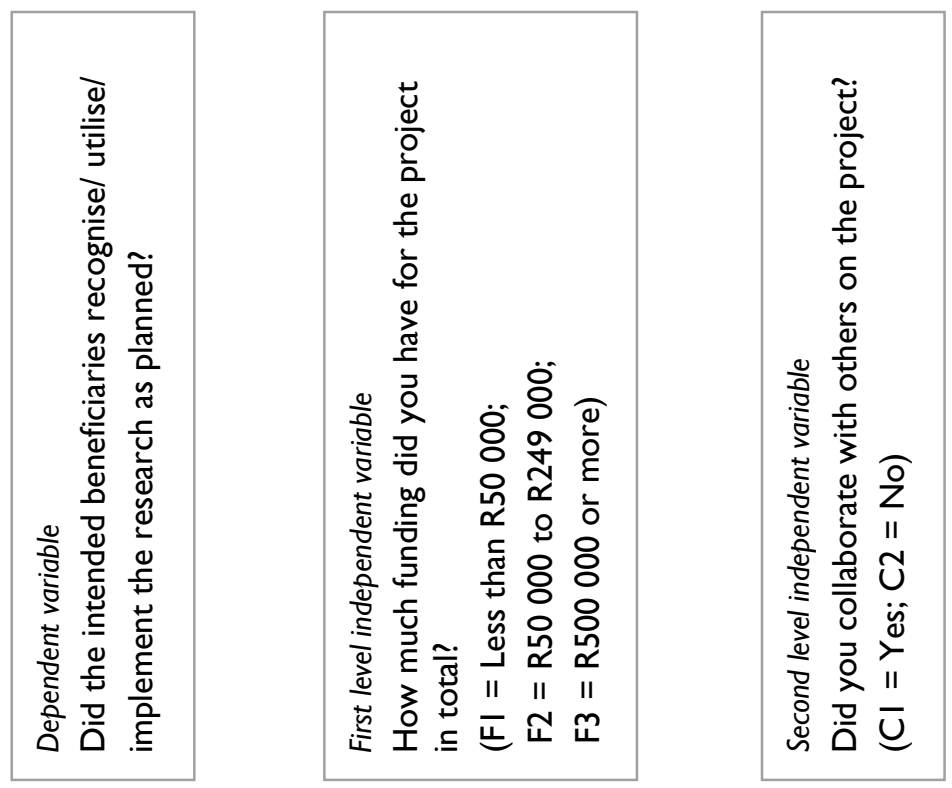

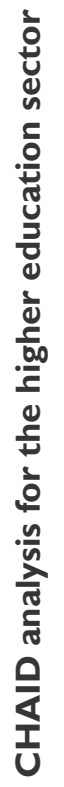

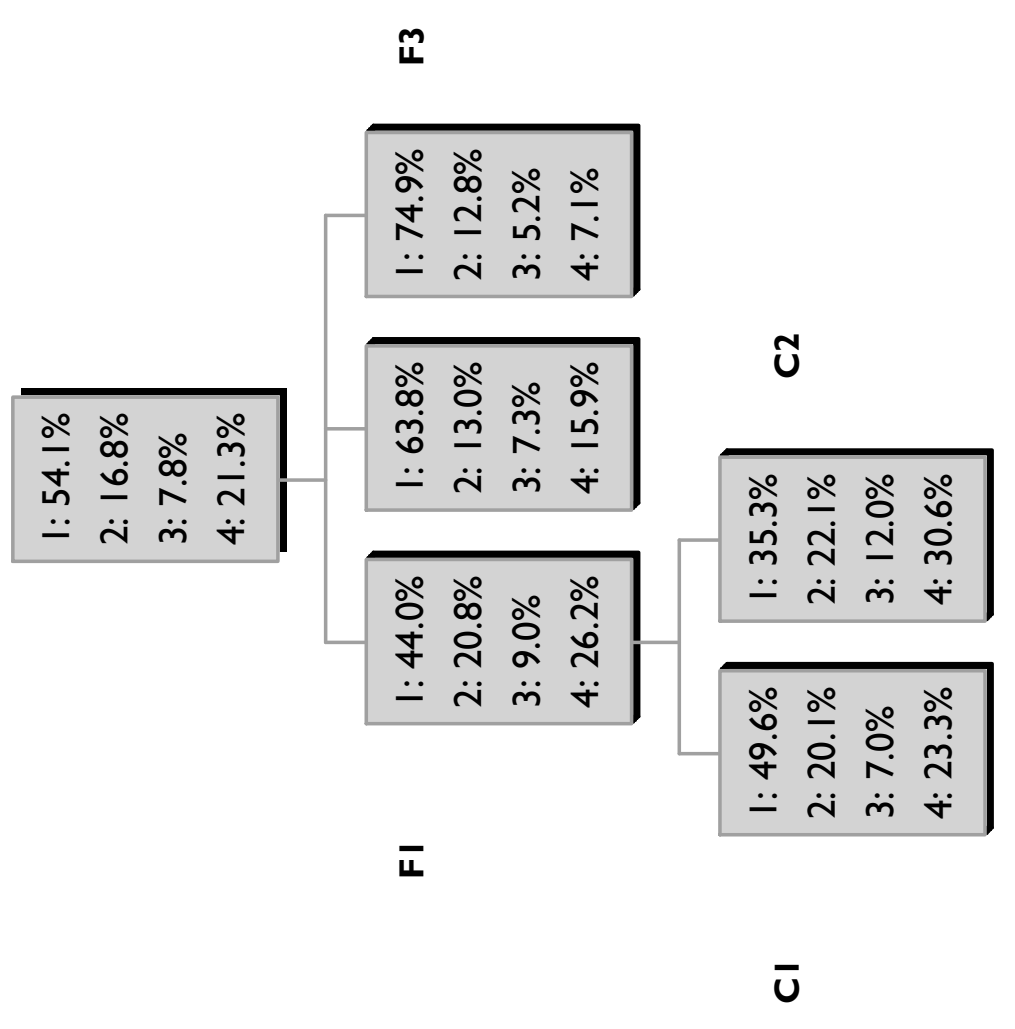


In Figure 3.9 the size of the project funding is the single most important predictor of research utilisation in the higher education sector: the higher the total amount of funding procured, the greater the utilisation of the research outcome $(75 \%$ utilisation when funding is more than R250 000). Collaboration has entered the analysis as a second level independent variable, for projects where the funding is less than R50 000.

Below are breakdowns by sector of collaboration (Table 3.28) and science culture (Table 3.29), based on the number of projects that have been utilised to some extent.

Table 3.28 Breakdown by sector of collaboration and project funding (higher education projects with collaboration)

\begin{tabular}{|c|c|c|c|c|c|c|}
\hline \multirow{2}{*}{ Collaborated with } & \multicolumn{2}{|c|}{ Less than R50 000} & \multicolumn{2}{|c|}{ R50 000 - R249 000} & \multicolumn{2}{|c|}{ R250 000+ } \\
\hline & $\%$ & $\mathbf{N}$ & $\%$ & $\mathbf{N}$ & $\%$ & $\mathbf{N}$ \\
\hline Academics/scholars & 50.9 & 336 & 64.5 & 211 & 75.4 & 179 \\
\hline Government & 45.8 & 48 & 58.8 & 34 & 84.0 & 50 \\
\hline Science council(s) & 62.5 & 16 & 76.9 & 13 & 59.1 & 22 \\
\hline NGOs & 70.0 & 30 & 72.2 & 18 & 83.3 & 36 \\
\hline Industry/ business & 49.2 & 63 & 75.5 & 53 & 81.5 & 81 \\
\hline
\end{tabular}

In Figure 3.9, when funding is highest (R250 $000+)$ no other predictor could significantly better the research utilisation. But if we cross-tabulate the projects in this funding category by sector of collaboration, it is predominantly projects with collaboration in government, NGOs and business/industry that seem to be more utilised. Collaboration with science councils appears least important for utilisation when funding is optimal (Table 3.28).

According to Table 3.29 large-scale projects (in terms of funding, i.e. R250 000+) have a greater chance of being utilised when the project is of an interdisciplinary nature. The same applies to small-sized projects (where funding is less than R50 000).

Table 3.29 Breakdown by science culture and project funding (higher education projects with collaboration)

\begin{tabular}{|l|l|l|l|l|l|l|}
\hline \multirow{2}{*}{ Science culture } & \multicolumn{3}{l}{ Less than R50 000} & R50 000 & R249 000 & \multicolumn{2}{l|}{ R250 000+ } \\
\hline & $\%$ & $\mathbf{N}$ & $\%$ & $\mathbf{N}$ & $\%$ & $\mathbf{N}$ \\
\hline Social sciences & 42.2 & 327 & 67.4 & 86 & 69.8 & 43 \\
\hline Natural sciences & 43.0 & 135 & 61.0 & 100 & 74.5 & 106 \\
\hline Health \& medical sciences & 41.3 & 63 & 61.9 & 21 & 76.5 & 17 \\
\hline Interdisciplinary social sciences & 50.5 & 105 & 59.5 & 42 & 79.3 & 29 \\
\hline Natural and health \& medical sciences & 53.8 & 26 & 69.2 & 26 & 80.0 & 15 \\
\hline
\end{tabular}




\subsubsection{Selected clusters of research domain}

As a matter of interest, and to investigate the robustness of collaboration as a determinant of research utilisation, we have conducted three more CHAIDs for selected combinations of research domain: ${ }^{3}$

$<$ Arts and humanities, economic and management sciences, and social sciences combined

$<$ Engineering sciences and applied sciences and technologies combined

$<$ Agricultural and environmental sciences combined

The following served as independent variables:

- Institution ( 1 = Science councils; 2 = Universities; 3 = Technikons)

- How long have you been involved in research? ( I = Median or below; 2 = Above median $)$

- Did you collaborate with others on the project? $(I=$ Yes; $2=\mathrm{No})$

- Approximately how much of your total working time did you devote to this project during the course of the project? ( I = 10-20\%; $2=30-40 \% ; 3=50 \%+)$

Results are shown in Figures 3.10 to 3.12. For two of the three CHAIDs collaboration again emerged as the strongest determinant of research utilisation. The exception is agricultural and environmental sciences where institutional affiliation provided the best classification.

\footnotetext{
${ }^{3}$ Meaningful clusters were required to ensure a minimum of 500 projects per CHAID analysis.
} 


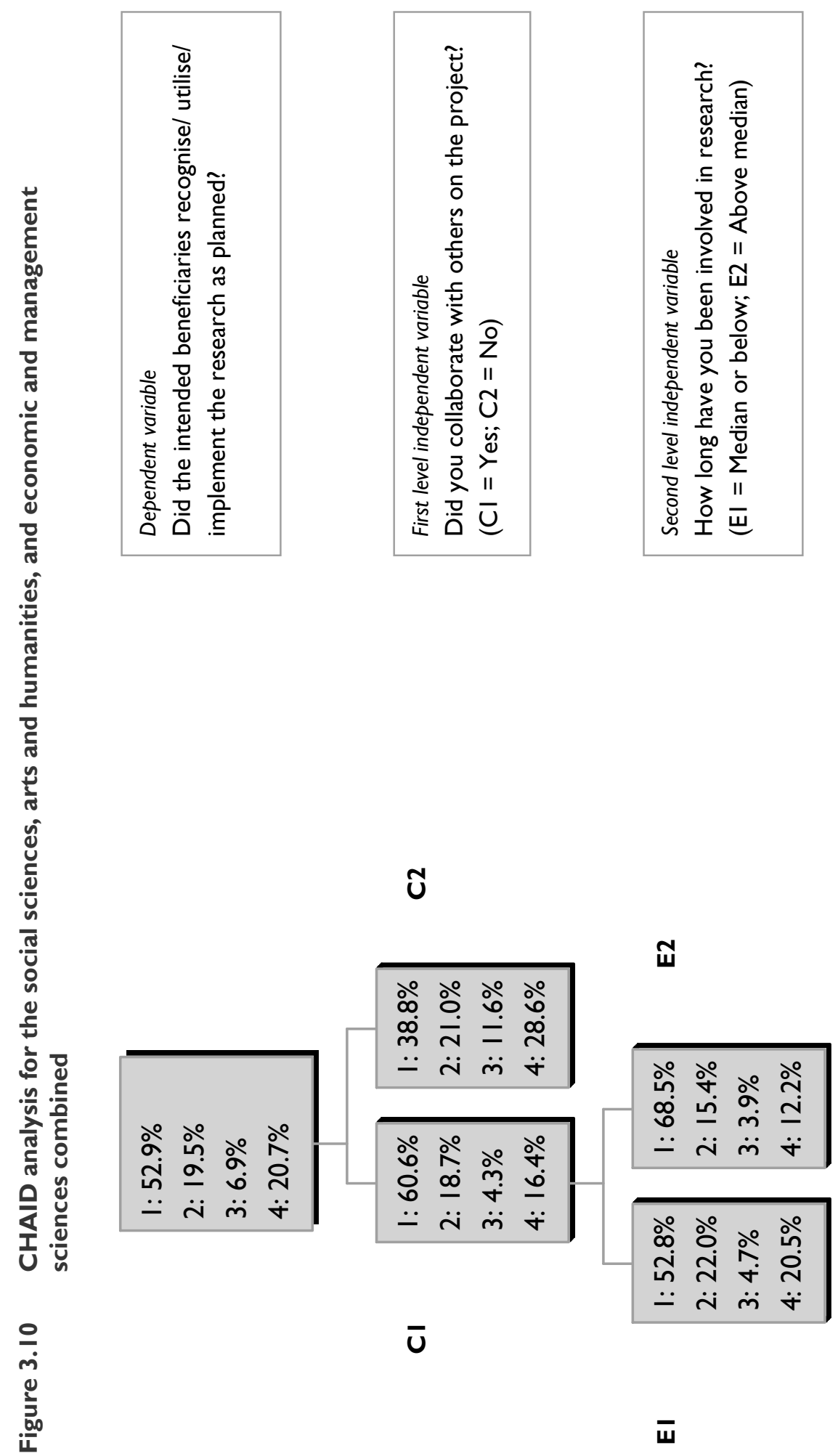




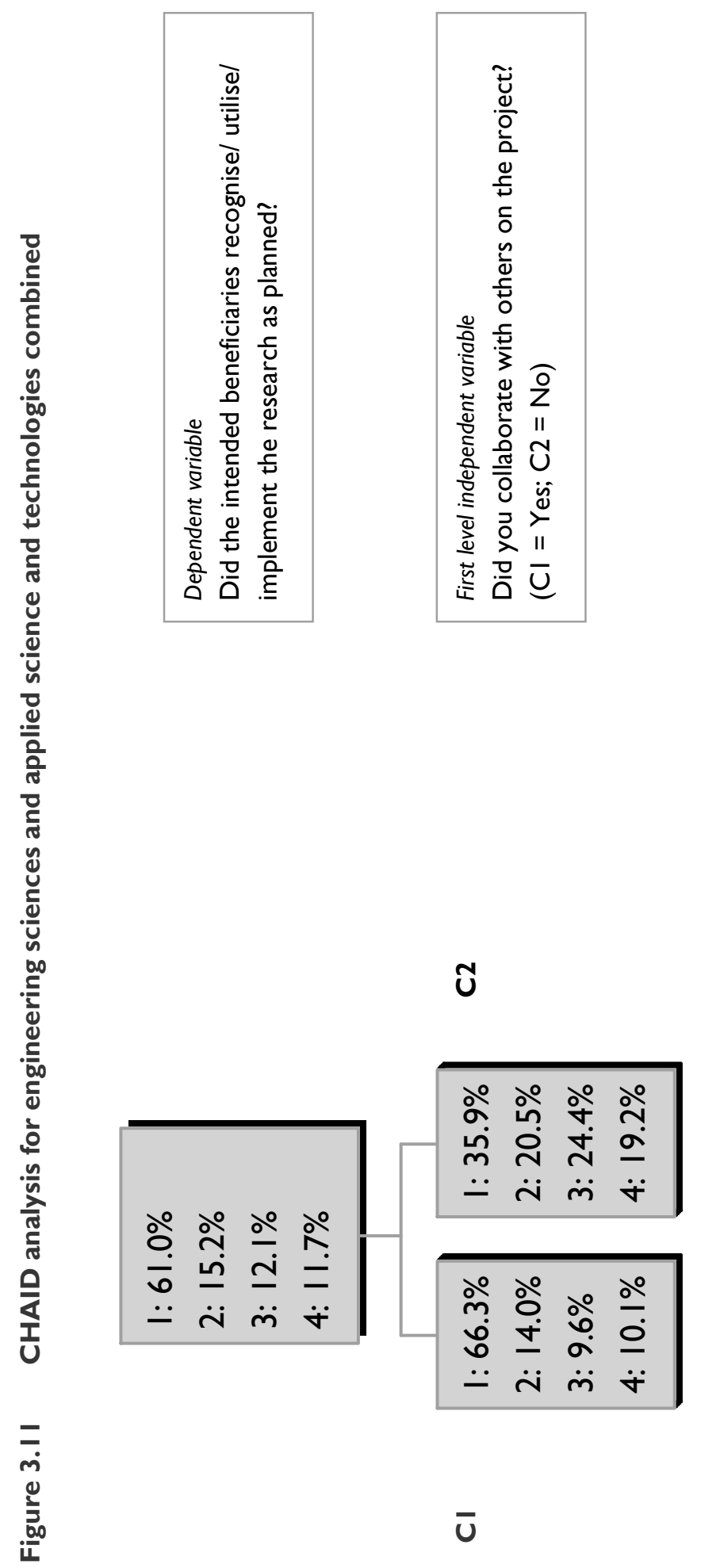




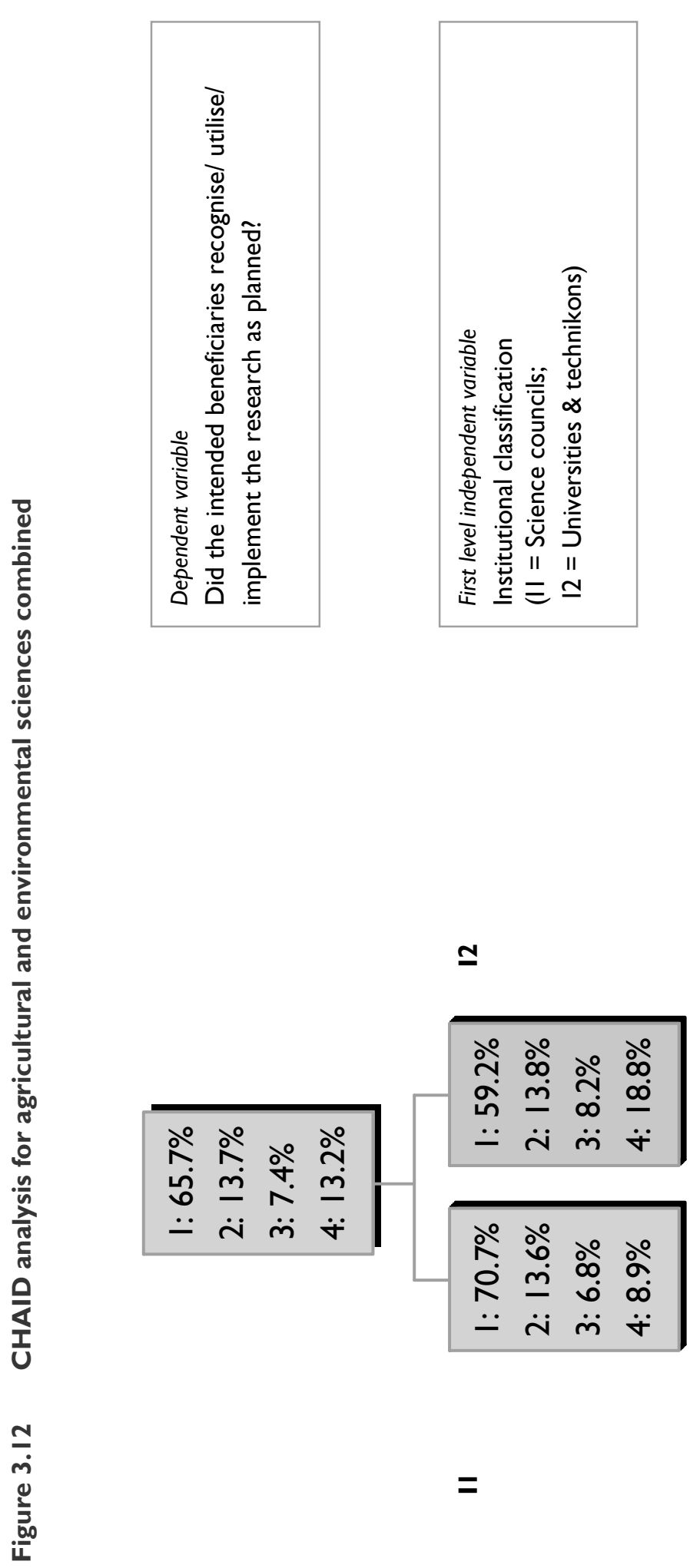


The results of the three CHAID-analyses showed quite marked differences between the three domains. In the case of the social sciences and humanities, whether collaboration occurred or not emerged as the most important predictor, followed by the differences in the research experience of the project leader (Table 3.30). Whether collaboration took place or not was the only significant correlate in the case of the engineering and applied technological sciences. Where collaboration was reported, effective utilisation was reported for $66 \%$ of the projects; where there was no collaboration reported, the percentage of reported utilisation of research findings dropped to 36\% (Figure 3. I I).

Table 3.30: Predictors of effective utilisation in the case of the social sciences and humanities

\begin{tabular}{|l|l|l|}
\hline Predictor & $\begin{array}{l}\text { \% effective } \\
\text { utilisation }\end{array}$ & $\begin{array}{l}\text { N of } \\
\text { projects }\end{array}$ \\
\hline $\begin{array}{l}\text { Collaboration with other researchers and above average } \\
\text { research experience of project leader }\end{array}$ & $\mathbf{6 8 . 5 \%}$ & $\mathbf{2 5 4}$ \\
\hline $\begin{array}{l}\text { Collaboration with other researchers and below average } \\
\text { research experience of project leader }\end{array}$ & $\mathbf{5 2 . 8 \%}$ & $\mathbf{2 5 4}$ \\
\hline \begin{tabular}{l} 
No collaboration with other researchers/projects \\
\hline
\end{tabular} & $\mathbf{3 8 . 8} \%$ & $\mathbf{2 7 6}$ \\
\hline
\end{tabular}

As far as the agricultural and environmental sciences are concerned, the institutional sector (science councils vs. higher education sector) turned out to be the only significant correlate. Research projects being undertaken within the science council sector (predominantly within the Agricultural Research Council) was reported has being effectively utilised in $71 \%$ of the cases, whereas for the universities and technikons this percentage was a much lower $59 \%$. 
The salient results, which have emerged from the questionnaire survey, can be summarised in the form of five key propositions:

PROPOSITION | The utilisation of research takes on a variety of forms ranging from the advancement of knowledge to changing human behaviour, developing new technologies and solving applied problems. All forms of utilisation are evident in the research projects described in this study.

The most highly cited expected outcomes from research (advancement of knowledge, skills development, research capacity building) all refer to outcomes that are to some extent within the control of the researcher (Table 3.9). Those outcomes that are less under the control of the researcher, such as changing human behaviour, informing legislation and entrance into new markets, were reported as occurring with lower probabilities than the first category. More theoretical outcomes (advancing knowledge) were rated as being more likely to occur than more practical outcomes (solving applied problems).

These results can be used to develop a typology that plots the various expected outcomes along two dimensions: the degree of control and theory-practice continuum (Figure 4.I). The interesting and crucial point about research utilisation that is made more explicit by this two-dimensional plotting of the responses, is that the utilisation of research is a function not only of the nature of the expected outcome of the R\&D process, but also the degree of control over the further path or trajectory of the outcomes of the R\&D process. 


\section{Figure 4.I: Two-dimensional plotting of outcomes of R\&D process}

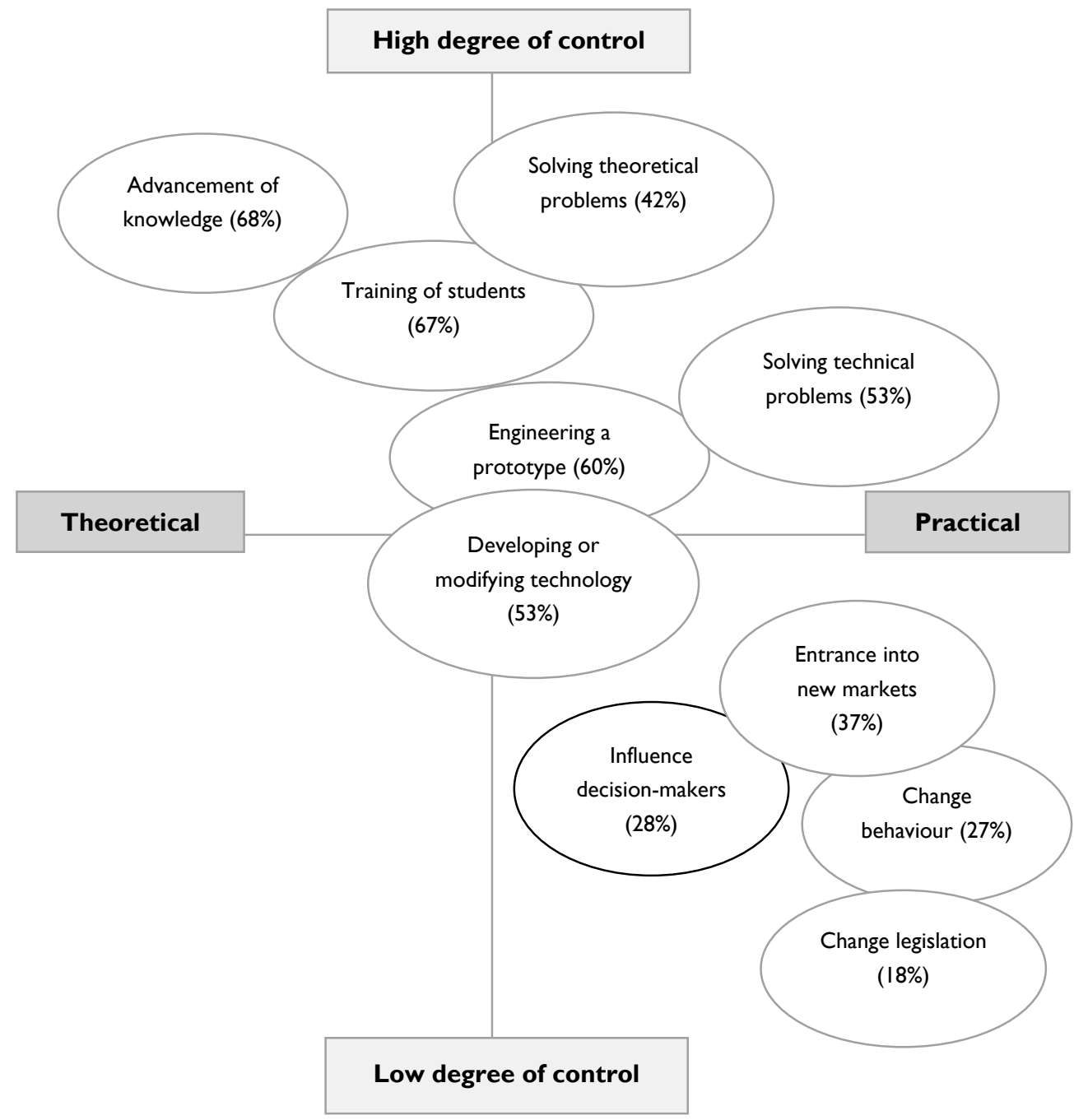

As far as the theory-practice dimension is concerned, we have to remind ourselves that scientific research or inquiry typically produces research outputs of two kinds: 'epistemic' or 'knowledge' outputs and 'non-epistemic' outputs or knowledge applications (Bailey and Mouton, 2005). Epistemic outputs include all forms of new knowledge: new theories, interpretations, insights, models, hypotheses, conjectures, facts, data as well as instrumentation. Epistemic outputs (or 'new knowledge') in turn, can be divided into codified or embedded (or 'tacit') knowledge. Codified knowledge is knowledge that has been 'written up' and which is usually transmitted to a particular audience in a standard form such as a scientific presentation, paper, book, report, electronic communication and so on. Embedded knowledge refers to the knowledge (including skills, competencies) that is embedded in people. 
Non-epistemic outputs include all forms of application and technology that flow from the research process. These include process and product technologies and artefacts as well as social science applications such as policies, programmes, interventions, tests, scenarios, strategies, plans, systems, and many more.

These distinctions are incorporated into a heuristic framework (Figure 4.2 below) on the relationship between modes of knowledge production and utilisation.

Different modes of knowledge production clearly have different intended or unintended audiences (or target groups, beneficiaries, user groups) in mind. We expand this principle in the framework by including the most important audiences of research: the scientific community, the market/industry, society and government.

And finally, we introduce in the framework reference to the various properties of research (outputs): volume or quantity, quality or merit, importance, marketability, utility or benefit and relevance. These six properties are often encountered in R\&D evaluation studies where the focus is on evaluating or assessing research in terms of one or more of its properties. So, for instance, we might wish to assess the volume of research output of an individual scientist or centre over time. Or we might be interested in comparing the quality or merit of different scientists for purposes of promotion or funding through peer review.

\section{Figure 4.2 A framework of the production and utilisation of knowledge}

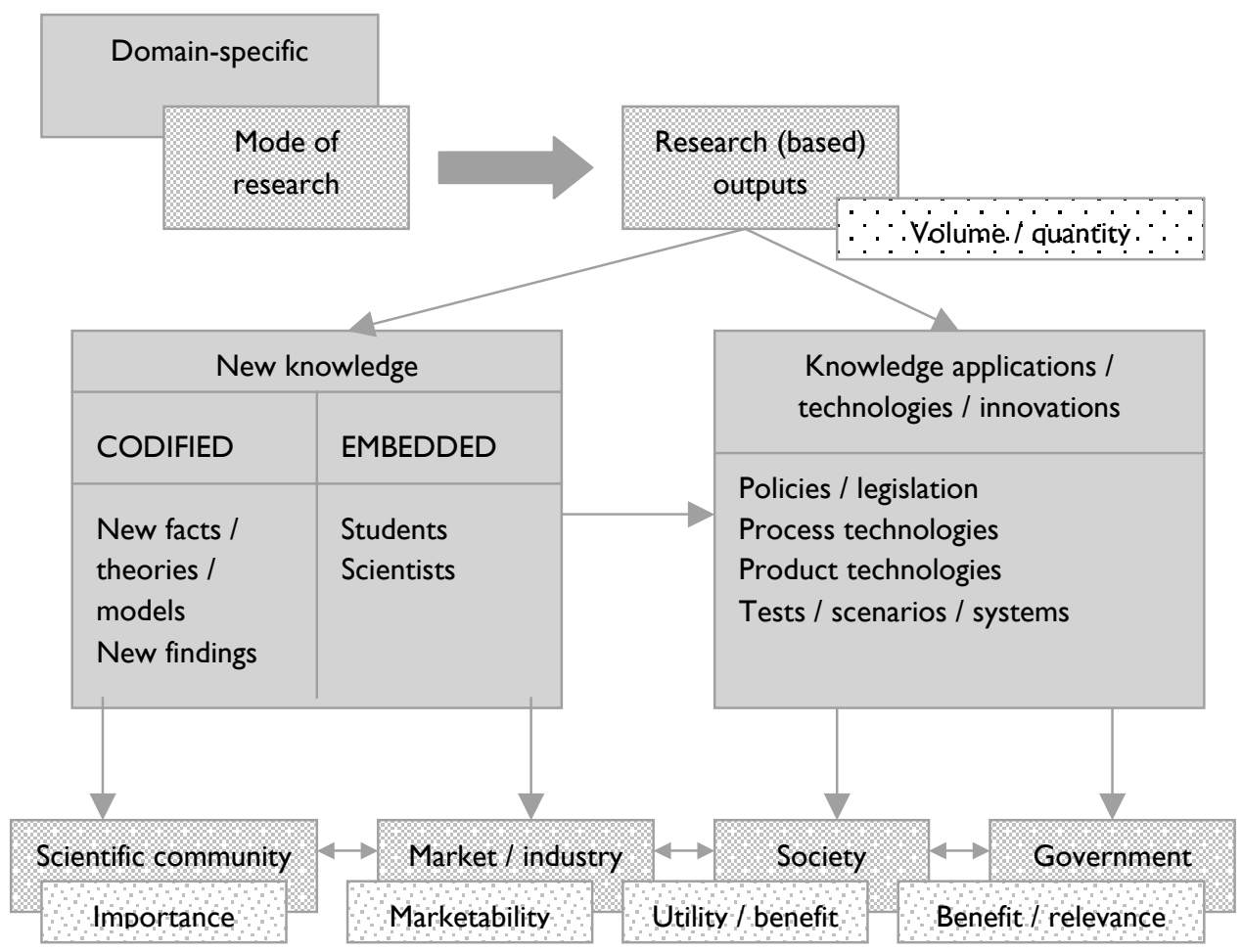


If we relate the results of our survey to the framework above, it becomes clearer why the reported expected outcomes of research vary across the two dimensions identified. What we termed the "theoretical outcomes" (advancement of knowledge, skills development and - to some extent - research capacity building") refer to epistemic outputs. The more practical outcomes (development of new technology, modification of existing technology, changing behaviour, informing policy and legislation) are all examples of "knowledge applications".

The value of the survey results is that it has alerted us to the importance of the second dimension: the degree of control over research outputs. Some outcomes of research such as solving theoretical problems or adding to our knowledge of the world - are more clearly within the control of the researcher. Other outcomes are much more clearly outside of the control of the researcher - entrance into new markets, changing human behaviour and informing legislation.

Another way of explaining these results is to propose a distinction between factors internal to the R\&D process (those within the control of the researcher) and those external to the research process (e.g. market forces, political dynamics, the vagaries of human behaviour, cost of utilisation, etc.). The obvious value of this distinction is that it would impact on strategies for promoting research utilisation: strategies that aim to increase theoretical/epistemic outputs will differ from those aimed at increasing the utilisation of knowledge applications.

PROPOSITION 2 How one interprets the extent of research utilisation depends on one's definition of "utilisation". If one accepts a broad definition, the survey results suggest fairly significant levels of successful utilisation. If one takes a more limited definition as the point of departure, the survey results paint a much bleaker picture of low levels of research utilisation.

In our review of the literature, we made the following distinction: The term 'research utilisation' can be understood either in a narrow or broad sense. In the narrow sense, the utilisation of research refers to the economic or commercial utility of research, i.e. how science is useful for economic growth or commercial aims. In the broader sense, research utilisation refers to any form of use that scientific research (results) is put to. So, in addition to economic or commercial utility, we could also include social utility (use of research for society at large) and political utility (science in support for political decisionmaking). We will refer to these as non-epistemic forms of utilisation.

But even this broadening of the meaning does not cover all possible forms of research use. We also need to remind ourselves that science (at least 'basic' or 'fundamental' science) is first and foremost aimed at the advancement of knowledge and increasing our understanding of the world. Some would argue that no use is intended or anticipated within a fundamental science paradigm. This is only true if 'use' is reserved for the narrow meaning of 'economic' or 'applied' use. But other scientists of course, use fundamental science. One scientist 'uses' another's findings or uses a model or framework developed by another. We often talk about 'applying' the insights gained in one study to another. We 
will refer to this as the epistemic utility of scientific research: research for the sake of (producing) knowledge.

Based on this distinction, we can group the various expected outcomes listed by project leaders into three groups (Cf. Table I below) viz. epistemic utility (mainly knowledge products/outputs), economic utility (new technologies and commercial products) and social utility (social benefits). We should also remind ourselves that epistemic utility comprises both codified and tacit or embedded knowledge products.

\section{Table 4.I: Expected research outcomes classified as 'epistemic', 'economic' and 'social' utility}

\begin{tabular}{|c|c|c|}
\hline Epistemic utility (knowledge) & Economic utility & Social or political utility \\
\hline Advancement of knowledge & $\begin{array}{l}\text { Solving technical or applied } \\
\text { problems }\end{array}$ & $\begin{array}{l}\text { Solving social/environmental } \\
\text { problems }\end{array}$ \\
\hline Solving theoretical problems & $\begin{array}{l}\text { Development of a new } \\
\text { technology }\end{array}$ & Influencing decision-makers \\
\hline Skills development & Engineering a prototype & Changing behaviour \\
\hline \multirow[t]{2}{*}{ Training of students } & $\begin{array}{l}\text { Modification of existing } \\
\text { products and designs }\end{array}$ & Changing legislation \\
\hline & Entrance into new markets & \\
\hline
\end{tabular}

The responses to two questions posed in the survey allow us to estimate, to some degree, the extent or scope of research being utilised. Respondents were first asked to list the most likely outcomes that would be produced by their research. These responses, ranked in descending order, were reported in Table 3.8. In a follow-up question, respondents were asked to indicate whether they believed the outcome had been successfully attained. Three options were given: highly successful, successful to some extent, and not successful at all. By combining the responses to these two questions, we are able to estimate what proportion of research leads to the successful achievement of the expected outcomes. So, for example, $70 \%$ of respondents indicated that one of the expected outcomes of their research is the advancement of knowledge. In the follow-up question, a similar percentage $(68 \%)$ of respondents indicated that they believed that their research was highly successful in achieving this outcome. This means, in effect, that $48 \%$ ( $70 \%$ of 68 respondents) of all research reported on, was estimated to have been highly successful in leading to the advancement of knowledge. In this case, a further $30 \%$ indicated that they believe that their research was to some extent successful in achieving this outcome. Table 4.2 presents the findings of these two combined questions (reporting on the "highly successful attainment" and "successful to some extent" options) for all expected outcomes. The results are categorised according to the three main categories of research utility. 
Table 4.2: Successful research utilisation

\begin{tabular}{|c|c|c|c|c|c|}
\hline $\begin{array}{l}\text { Epistemic utility } \\
\text { (knowledge) }\end{array}$ & 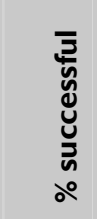 & Economic utility & 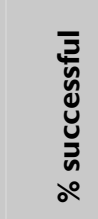 & $\begin{array}{l}\text { Social or political } \\
\text { utility }\end{array}$ & 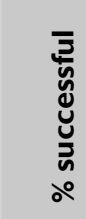 \\
\hline $\begin{array}{l}\text { Advancement of } \\
\text { knowledge }\end{array}$ & $69 \%$ & $\begin{array}{l}\text { Solving of technical or } \\
\text { applied problems }\end{array}$ & $24 \%$ & $\begin{array}{l}\text { Solving social and } \\
\text { environmental } \\
\text { problems }\end{array}$ & $20 \%$ \\
\hline $\begin{array}{l}\text { Solving theoretical } \\
\text { problems }\end{array}$ & $13 \%$ & $\begin{array}{l}\text { Development of a new } \\
\text { technology }\end{array}$ & $14 \%$ & $\begin{array}{l}\text { Influencing decision- } \\
\text { makers }\end{array}$ & $19 \%$ \\
\hline Skills development & $32 \%$ & $\begin{array}{l}\text { Modification of existing } \\
\text { products and designs }\end{array}$ & $8 \%$ & Changing behaviour & $17 \%$ \\
\hline \multirow[t]{2}{*}{ Training of students } & $29 \%$ & $\begin{array}{l}\text { Engineering a } \\
\text { prototype }\end{array}$ & $3 \%$ & Changing legislation & $3 \%$ \\
\hline & & $\begin{array}{l}\text { Entrance into new } \\
\text { markets }\end{array}$ & $3 \%$ & & \\
\hline
\end{tabular}

PROPOSITION 3 Reported effective utilisation of research is clearly related to the type of R\&D concerned.

In our development of a heuristic framework to assist in the explanation of factors influencing research utilisation (Bailey and Mouton 2005), we formulated the following proposition: Forms of research utilisation are strongly influenced by the nature of the research/mode of knowledge production (research modes / modes of knowledge production).

Applying the standard Frascati distinction between basic fundamental, basic strategic and applied research, we elaborated on these distinctions further. The results are summarised in Table 4.3. 


\begin{tabular}{|c|c|c|c|c|c|c|}
\hline$\frac{0}{\frac{0}{0}}$ & : & 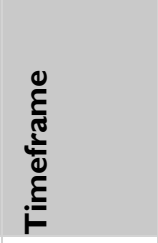 & $\frac{\stackrel{0}{U}}{\frac{c}{0}}$ & 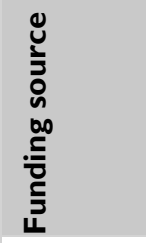 & 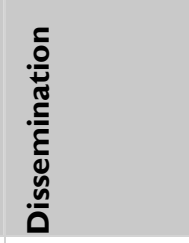 & 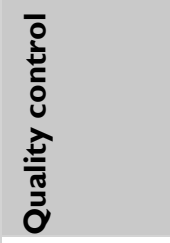 \\
\hline Fundamental & Curiosity & Indefinite & $\begin{array}{l}\text { World of } \\
\text { science }\end{array}$ & $\begin{array}{l}\text { Scarce } \\
\text { Own } \\
\text { institution } \\
\text { Public } \\
\text { funding }\end{array}$ & $\begin{array}{l}\text { Scientific } \\
\text { publications/ } \\
\text { Presentations }\end{array}$ & Peer review \\
\hline Strategic & $\begin{array}{l}\text { Curiosity } \\
+ \text { Utility }\end{array}$ & Long-term & $\begin{array}{l}\text { World of } \\
\text { science and } \\
\text { other as yet } \\
\text { unidentified } \\
\text { beneficiaries }\end{array}$ & $\begin{array}{l}\text { Public } \\
\text { funding } \\
\text { Other } \\
\text { sources }\end{array}$ & $\begin{array}{l}\text { Scientific } \\
\text { forms }\end{array}$ & $\begin{array}{l}\text { Peer review/ } \\
\text { Potential } \\
\text { users }\end{array}$ \\
\hline Applied & Utility & $\begin{array}{l}\text { Short- to } \\
\text { medium- } \\
\text { term }\end{array}$ & $\begin{array}{l}\text { Specific } \\
\text { users/ } \\
\text { beneficiaries }\end{array}$ & $\begin{array}{l}\text { Private } \\
\text { funding }\end{array}$ & $\begin{array}{l}\text { Confidential } \\
\text { contract } \\
\text { reports/ } \\
\text { strategic } \\
\text { briefings }\end{array}$ & $\begin{array}{l}\text { User } \\
\text { satisfaction }\end{array}$ \\
\hline
\end{tabular}

It is important to realize that the mode of research already 'pre-determines' or at least 'influences' the following:

$<$ The form and channels of dissemination

$<$ The perceived value of the research output (scientific/social/economic)

$<$ The intended target audience or beneficiaries of the research output(s).

The relationship between "modes of knowledge production" or "type of R\&D" and reported utilisation of research is clearly demonstrated in Figure 4.3 below when the motive behind the research and reported utilisation are cross-tabulated. Higher reported utilisation is evidently related to those "triggers" of research that concern commissions from outside firms or companies or contracted research. At the other end of the scale, we find that research that is driven more by curiosity has lower levels of reported utilisation. 
Figure 4.2: Triggers of research and effective utilisation

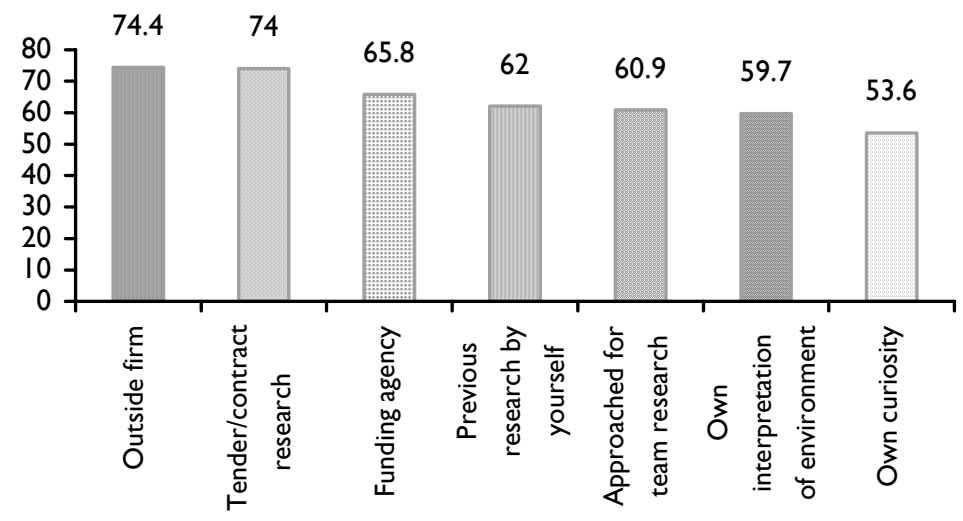

PROPOSITION 4 The multivariate analysis has unequivocally shown that the utilisation of research/knowledge is correlated highly with four key factors. These are whether there is evidence of research collaboration in the project and with whom there is collaboration; the research experience of the project leader and the size of the project as measured in the amount of project funding.

The fact that these four factors correlate highly with "reported" effective utilisation does, of course, not imply any causal relationship. However, it does force us to investigate further the possible reasons that could explain these correlations.

Collaboration means increased access to scientific resources: more funding, more extensive research networks, the potential utility of a larger pool of stakeholders, and so on. The fact that project leaders have reported a much higher likelihood of effective utilisation when there has been a history of collaboration in the project might be interpreted to mean that effective utilisation is more likely to occur when the project has access to intellectual and social resources such as these.

Equally important is the "locality" of those that one collaborates with. Collaborating with other scholars in one's own sector is important but does not necessarily results in access to new resources - only to more of the same. But collaboration with scientists and nonscientists in other sectors of the national innovation system - such as government, industry and NGOs - does imply possible access to new resources - new sources of funding, new networks and communities. It is, therefore, not surprising that reported utilisation is higher when collaboration is across sectors and outside of R\&D institutions.

The fact that the research experience of the project leader has emerged as a significant predictor of effective utilisation is compatible with the collaboration factors. But it raises additional points. Experienced researchers not only have more extensive networks (the point about collaboration), but it also suggests better project management skills and better utilisation of the available research resources. Both of these factors could enhance the likelihood of research utilisation. 
And finally, the size of the project - as measured in terms of project funding - was significantly correlated with successful utilisation. Again, this suggests that larger projects, which have access to more resources (more researchers/ equipment/ infrastructure/ more intellectual capital in the form of networks), are more likely to lead to effective utilisation.

In conclusion: effective utilisation, to the extent that it is within the control of the project leader (or team), is more likely to occur where researchers collaborate - especially across R\&D institutions and sectors, where there are experienced project leaders in charge of such projects and where there is a critical mass of resources (including funding) available to the team.

PROPOSITION 5 The effective utilisation of R\&D does occur differently across different scientific domains and within different institutional settings.

The results with regard to main scientific domain, presented in Table 3.17, show a wide range of reported utilisation: from nearly $70 \%$ in the case of the agricultural sciences to just above $50 \%$ for the mathematical sciences. Cross tabulations with motives of research have shown that these results can be explained to some extent by the fact that those scientific domains which reported lower expected utilisation (mathematics and social sciences) are also more highly correlated with more fundamental research interests (e.g. own curiosity).

In order to assess how different predictor variables are related to reported effective utilisation for different science domains, we conducted separate CHAID-analyses for the humanities and social sciences, the engineering and applied technological sciences, and the agricultural and environmental sciences. The results for these three broad science domains (Section 3.4.4) are important because they suggest that institutional context is another important factor in understanding the dynamics that underpin the effective utilisation of research findings. The fact that research being undertaken within the science council sector (as graphically illustrated by the example of the agricultural sciences) generally reported higher utilisation, is yet another indication that the nature of R\&D conducted - which is also correlated with science domain - is a strong predictor of whether utilisation takes place or not.

Despite the increasing blurring of boundaries between the science councils and higher education institutions, it is still fair to say that more applied and applications-driven research occurs within the science councils. In terms of the Bozeman model: the demand environment that influences R\&D within science councils places a higher premium on applied and commissioned research that will produce results. Conversely, although there has been a noticeable shift towards applied and Mode 2 forms of research within South African universities and technikons over the past decade, it is still the case that basic fundamental and curiosity-driven research is found more within these institutions than anywhere else. 


\section{LIST OF REFERENCES}

Bailey TG \& Mouton J (2005) A review of models of research utilisation. The production and utilisation of knowledge in higher education institutions in South Africa. Volume I. Centre for Research on Science and Technology: University of Stellenbosch.

Barre R (200I) The agora model of innovation systems: S\&T indicators for a democratic knowledge society. Research Evaluation, I0(I): I3-18.

Bozeman B (2000) Technology transfer and public policy: A review of research and theory, Research Policy, 29:627-655

Carstens A \& Mouton J (2002) Industry-higher education partnerships: Literature review. Centre for Interdisciplinary Studies, University of Stellenbosch.

Crush J; McDonald D \& Williams V (2000) Is South Africa losing its minds? In Losing our minds: Skills migration and the South African brain drain, (ed) J Crush. Cape Town: Idasa.

Etzkowitz H \& Webster A (1998) Entrepreneurial science: The second academic revolution. In Etzkowitz $\mathrm{H}$; Webster A \& Healey $\mathrm{P}$ (eds.) Capitalizing knowledge: New intersections of industry and academia. Albany: State University of New York Press.

Etzkowitz, H, Webster A \& Healey P (1998) Introduction. In Etzkowitz H; Webster A \& Healey P (eds.) Capitalizing knowledge: New intersections of industry and academia. Albany: State University of New York Press.

Gibbons M; Limoges C; Nowotny H; Schwartzman S; Scott P \& Trow M (1994) The new production of knowledge. The dynamics of science and research in contemporary societies. London: SAGE Publications.

Hellström T \& Jacob M (2000) Emerging issues in R\&D evaluation: The case of universityindustry partnership networks. In Jacob M \& Hellström T (eds.) The future of knowledge production in the academy. Buckingham: Open University Press.

Hemlin S (1998) Utility evaluation of academic research: Six basic propositions. Research Evaluation, Vol. 7(3): I59-165.

Howells J \& James A (200I) Corporate decision-making on the sourcing of technological knowledge. PREST Discussion Paper O I-O I. Policy Research in Engineering, Science \& Technology, University of Manchester.

Huberman M (1994) Research utilisation: The state of the art. Knowledge and Policy: The International Journal of Knowledge Transfer and Utilisation. Vol. 7 (4): I3-33.

Leydesdorff L \& Etzkowitz H (1998) The Triple Helix as a model for innovation studies. (Conference Report). Available online at http://home.pscw.uva.nl/lleydesdorff/th2/spp.htm

Leydesdorff L \& Etzkowitz H 200I. The transformation of university-industry-government relations. (Electronic Journal of Sociology). Available online at http://www.sociology.org/content/vol005.004/ht.html

Machlup F (1993) Uses, value and benefits of knowledge. Knowledge: Creation, Diffusion, Utilisation. Vol. 14(4): 448-466.

Mattes R; Crush J \& Richmond W (2000) The brain gain: Skilled migrants and immigration policy in post-apartheid South Africa, Migration Policy Series, No. 20. Cape Town: Idasa/South African Migration Project. 
Mattes R \& Richmond W (2000) The brain drain: What do skilled South Africans think? In Losing our minds: Skills migration and the South African brain drain (ed) J Crush.

Migration Policy Series No. 18. Cape Town: Idasa/South African Migration Project

Mouton, J (2000) Patterns of research collaboration in academic science in South Africa. SA Journal of Science Vol.96 (Nrs. 9 \& I0): 458-462.

Mouton J (200I) Between adversaries and allies: The call for strategic science in postapartheid South Africa. Society in Transition.

OECD (199I) Oslo Manual: Proposed guidelines for collecting and interpreting technological innovation data. Paris: Organisation for Economic Co-operation and Development.

OECD (1994) Frascati Manual 1993: Proposed standard practice for surveys of research and experimental development. Paris: Organisation for Economic Co-operation and Development.

Orr L ( 1997) Globalisation and universities: Towards the 'market university'? Social Dynamics, 23(I):42-67.

Rich RF (1997) Measuring knowledge utilisation: Process and outcomes. Knowledge and Policy: The International Journal of Knowledge Transfer and Utilisation. Vol. 10 (3): II-24.

Rogers J \& Bozeman B (200I) "Knowledge value alliances": An alternative to the R\&D project focus in evaluation. Science, Technology and Human Values, Vol. 26 (I): 23-55.

Salter AJ \& Martin B (200I) The economic benefits of publicly funded basic research: A critical review. Research Policy 30: 509-532.

Scott A; Steyn G; Geuna A; Brusoni S \& Steinmeuller E (200I) The economic returns to basic research and the benefits of university-industry relationships: $A$ literature review and update of findings. Brighton: SPRU.

Subotzky G (1998) Alternatives to the entrepreneurial university: New modes of knowledge production in community service programs. Paper presented at the Annual ASHE International Conference, Miami, Florida, 4-7 November 1998.

Wickham S (2002) Unlocking intellectual knowledge: External partners' views of research partnerships with selected higher education institutions in the Western Cape. Report for the International Development Research Centre / Trade and Industry Policy Secretariat. University of Cape Town: Research \& Academic Development. 


\section{Appendix A}

Questionnaire: Higher Education Sector

\section{PUBLIC SECTOR R\&D IN SOUTH AFRICA: THE PRODUCTION AND UTILISATION OF RESEARCH}

\section{A. YOUR BACKGROUND}

I. Title:

2. Surname:

3. First names:

4. Institution:

5. Department/Centre/Division/Institute:

6. Position (e.g. senior lecturer):

7. How long have you been at your current institution?

8. Have you ever spent time in government or industry?

\begin{tabular}{|l|c|c|}
\cline { 2 - 3 } \multicolumn{1}{c|}{} & Yes & No \\
\hline Government & I & 2 \\
\hline Industry & I & 2 \\
\hline
\end{tabular}

\begin{tabular}{|c|}
\hline If yes, for how many years? \\
\hline$\ldots \ldots \ldots \ldots \ldots \ldots($ yrs $)$ \\
\hline$\ldots \ldots \ldots \ldots \ldots \ldots($ yrs $)$ \\
\hline
\end{tabular}

9. Highest educational qualification completed:

10. Gender:

\begin{tabular}{|l|l|}
\hline Female & I \\
\hline Male & 2 \\
\hline
\end{tabular}

II. Year of birth: 19

Please reflect on your research activities of the past five years (1997 to 200I). Think about your core research project that you are involved in. The project may be a recently completed one or still ongoing, but you must be the primary/principal investigator or project leader. Section B applies to this project that you select.

\section{B. CORE RESEARCH PROJECT}

12. Title:

13. Please give a brief description of the research topic (e.g. the quantification of resistances to blood flow in the lower limb arterial system using an inverse transmission line model; current trends in the selection of students for Higher Education, etc.) 
14. In which broad research domain(s) do the research activities mainly fall? (Tick all that apply.)

\begin{tabular}{|l|c|}
\hline Agricultural sciences & I \\
\hline Applied sciences and technologies & 2 \\
\hline Biological sciences & 3 \\
\hline Chemical sciences & 4 \\
\hline Earth sciences & 5 \\
\hline Engineering sciences & 6 \\
\hline Environmental sciences & 7 \\
\hline Humanities & 8 \\
\hline Information, computer and applied technologies & 9 \\
\hline Marine sciences & 10 \\
\hline Material sciences & $1 \mathrm{I}$ \\
\hline Mathematical sciences & 12 \\
\hline Medical and health sciences & 13 \\
\hline Physical sciences & 14 \\
\hline Social sciences & 15 \\
\hline
\end{tabular}

15. What triggered the research? (Tick all that apply.)

\begin{tabular}{|l|c|}
\hline Previous research by yourself & I \\
\hline Own curiosity & 2 \\
\hline Colleague(s) approaching you to form part of a team & 3 \\
\hline An outside firm/company/institution approaching you for assistance & 4 \\
\hline Own interpretation of the immediate environment & 5 \\
\hline A funding agency requesting a proposal & 6 \\
\hline A tender & 7 \\
\hline $\begin{array}{l}\text { Other } \\
\text { (Specify: ......................................................) }\end{array}$ & 8 \\
\hline
\end{tabular}

16. (a) What year did the programme start?

(year)

(b) What year did/will it end? (year)

17. (a) How much funding (grants, awards, contracts) do you have for the project in total (up to the end of 2001)?

\begin{tabular}{|l|l|}
\hline Less than RI0 000 & I \\
\hline RI0 000-R49 000 & 2 \\
\hline R50 000-R99 000 & 3 \\
\hline RI00 000 - RI99 000 & 4 \\
\hline R200 000 - R299 000 & 5 \\
\hline R300 000 or more & 6 \\
\hline
\end{tabular}

(b) Please tick the major source of funding:

\begin{tabular}{|l|l|}
\hline National Research Foundation & I \\
\hline THRIP & 2 \\
\hline Innovation Fund & 3 \\
\hline University/ Technikon & 4 \\
\hline Business/ private sector & 5 \\
\hline Overseas funder/ foundation & 6 \\
\hline Medical Research Council & 7 \\
\hline Agricultural Research Council & 8 \\
\hline Other (e.g. Water Research Commission) & 9 \\
Specify: ............................................... & \\
\hline
\end{tabular}


18. (a) Which TWO of the following best describe the overall expected value/ outcome of the research? (Tick the TWO that are most appropriate.)

\begin{tabular}{|l|c|}
\hline To advance/ improve knowledge & $\mathrm{I}$ \\
\hline To solve theoretical problems & 2 \\
\hline To solve immediate technical or applied problems & 3 \\
\hline To develop skills & 4 \\
\hline To train students & 5 \\
\hline To change behaviour/ attitudes/ values & 6 \\
\hline To influence decision-makers & 7 \\
\hline To change legislation & 8 \\
\hline To develop new technology & 9 \\
\hline To improve product or technical design & 10 \\
\hline To engineer a prototype & $\mathrm{II}$ \\
\hline To enter new markets & 12 \\
\hline $\begin{array}{l}\text { Other } \\
\text { (Specify: ................................................................) }\end{array}$ & 13 \\
\hline
\end{tabular}

(b) Please rate the extent to which you believe that the two expected values/ outcomes, on the whole, have been successful or not. (You need to write the two expected values/ outcomes - indicated in 18(a) -in the spaces below before rating them.)

\begin{tabular}{|c|c|c|c|}
\hline & 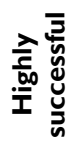 & 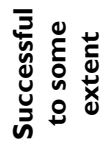 & 范 \\
\hline 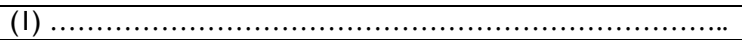 & $\mathrm{T}$ & 2 & 3 \\
\hline 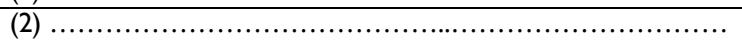 & $\mathrm{I}$ & 2 & 3 \\
\hline
\end{tabular}

19. Which intended beneficiaries did you have in mind when you conceptualised the research?

\begin{tabular}{|l|c|}
\hline Colleagues/ scholars/ peers in own discipline & I \\
\hline Colleagues/ scholars/ peers in other disciplines & 2 \\
\hline The contracting agency & 3 \\
\hline Industry/ firms & 4 \\
\hline Government & 5 \\
\hline General public & 6 \\
\hline $\begin{array}{l}\text { Specific interest groups (e.g. farmers, consumers) } \\
\text { (Specify: ....................................................................) }\end{array}$ & 7 \\
\hline $\begin{array}{l}\text { Other } \\
\text { (Specify: .............................................................) }\end{array}$ & 8 \\
\hline
\end{tabular}

20. Did the intended beneficiaries recognise/ utilise/ implement the research as planned?

\begin{tabular}{|l|l|}
\hline Yes, to some extent & I \\
\hline Yes, to little extent & 2 \\
\hline No, not at all & 3 \\
\hline Don't know & 4 \\
\hline
\end{tabular}

If yes (some/ little extent), please answer Questions $2 \mathrm{I}(\mathrm{a})$ and (b).

If no, please go to Question 22.

If you don't know, please go to Question 23.

21. (a) Please describe how the research has been utilised/ implemented/ applied by the intended beneficiaries. (Give concrete examples.) 
(b) What form of support has there been from your side? (Training, writing a manual, etc.)

\section{Go to Question 23.}

22. In your opinion, why hasn't the research been utilised/ implemented/ applied by the intended beneficiaries as planned?

.........................................

(n.

23. How did you communicate the results of your research? (Please indicate the mode of communication as well as the number of outputs - i.e. the number of articles, reports, books, patents, licenses, workshops etc that resulted from this project directly or indirectly.)

\begin{tabular}{|c|c|c|c|}
\hline Publications & Yes & \multicolumn{2}{|c|}{ No } \\
\hline Through articles in scientific journals & I & \multicolumn{2}{|c|}{2} \\
\hline Through articles in technical journals & $\mathrm{I}$ & \multicolumn{2}{|c|}{2} \\
\hline Through articles in popular journals & $\mathrm{I}$ & \multicolumn{2}{|c|}{2} \\
\hline Through contract reports & $\mathrm{I}$ & \multicolumn{2}{|c|}{2} \\
\hline Through books/ monographs & $\mathrm{I}$ & \multicolumn{2}{|c|}{2} \\
\hline Through chapters in books & $\mathrm{I}$ & \multicolumn{2}{|c|}{2} \\
\hline \multicolumn{4}{|l|}{ Presentations/ meetings } \\
\hline \multicolumn{2}{|l|}{ Through conferences with predominantly academic audiences } & $\mathrm{I}$ & 2 \\
\hline \multicolumn{2}{|l|}{ Through conferences with predominantly non-academic audiences } & $\mathrm{I}$ & 2 \\
\hline \multicolumn{2}{|l|}{ Through expert committees/ panels } & $\mathrm{I}$ & 2 \\
\hline \multicolumn{2}{|l|}{ Through public hearings } & $\mathrm{I}$ & 2 \\
\hline \multicolumn{2}{|l|}{ Through fairs/ exhibitions/ road shows/ public talks } & $\mathrm{I}$ & 2 \\
\hline \multicolumn{4}{|l|}{ Patents/ licences } \\
\hline \multicolumn{2}{|l|}{ Through patenting } & I & 2 \\
\hline \multicolumn{2}{|l|}{ Through licensing } & I & 2 \\
\hline \multicolumn{4}{|l|}{ Training } \\
\hline \multicolumn{2}{|l|}{ Through workshops } & I & 2 \\
\hline \multicolumn{2}{|l|}{ Through the training of postgraduate students } & I & 2 \\
\hline \multicolumn{4}{|l|}{ Cooperative interactions } \\
\hline \multicolumn{2}{|l|}{ Through consultations/ technical assistance to potential users } & I & 2 \\
\hline \multicolumn{2}{|l|}{ Through personnel exchanges/ secondments } & $\mathrm{I}$ & 2 \\
\hline \multicolumn{4}{|l|}{ Organisational structures } \\
\hline \multicolumn{2}{|l|}{ Through participation in consortia } & $\mathrm{I}$ & 2 \\
\hline \multicolumn{2}{|l|}{ Through science parks } & $\mathrm{I}$ & 2 \\
\hline \multicolumn{2}{|l|}{ Through spin-off companies } & $\mathrm{I}$ & 2 \\
\hline \multicolumn{2}{|l|}{ Through technology transfer offices } & $\mathrm{I}$ & 2 \\
\hline \multicolumn{2}{|l|}{ Through technology incubators } & $\mathrm{I}$ & 2 \\
\hline \multicolumn{2}{|l|}{$\begin{array}{l}\text { Other } \\
\text { (Specify: } \ldots \ldots \ldots \ldots \ldots \ldots \ldots \ldots \ldots \ldots \ldots \ldots \ldots \ldots \ldots \ldots \ldots \ldots \ldots)\end{array}$} & $\mathrm{I}$ & 2 \\
\hline
\end{tabular}
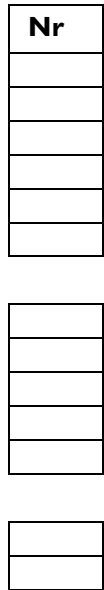

Training

Through workshops

Through the training of postgraduate students

Cooperative interactions

\section{Organisational structures}

Through participation in consortia

Through spin-off companies

Through technology transfer offices

Other

(Specify: 
24. How many postgraduate students got their degree through the research project? (number of masters students)

(number of doctoral students)

25. (a) Has there been any unintended beneficiaries of your research?

\begin{tabular}{|l|l|}
\hline Yes & I \\
\hline No & 2 \\
\hline Don't know & 3 \\
\hline
\end{tabular}

(b) If yes, please describe (i) who the unintended beneficiaries are and (ii) how they have utilised/ implemented/ applied the research.

(i)

(ii)

26. Is there anything else that you would like to raise? Anything not covered by this questionnaire or maybe something about the questionnaire itself? 
Questionnaire: Science Councils

\section{PUBLIC SECTOR R\&D IN SOUTH AFRICA: THE PRODUCTION AND UTILISATION OF RESEARCH}

A. YOUR BACKGROUND

I. Title:

\begin{tabular}{|l|l|}
\hline $\mathrm{Dr}$ & $\mathrm{I}$ \\
\hline $\mathrm{Mr}$ & 2 \\
\hline Mrs & 3 \\
\hline Ms & 4 \\
\hline Prof & 5 \\
\hline
\end{tabular}

2. Surname:

3. First names:

4. Institution:

5. Department/Centre/Division/Institute:

6. Position (e.g. senior lecturer):

7. How long have you been involved in research? (years)

8. Have you ever worked in government, industry or the higher education sector?

\begin{tabular}{|l|l|l|}
\cline { 2 - 3 } \multicolumn{1}{c|}{} & Yes & No \\
\hline Government & I & 2 \\
\hline Industry & I & 2 \\
\hline University & I & 2 \\
\hline Technikon & I & 2 \\
\hline
\end{tabular}

\begin{tabular}{|l|}
\hline If yes, for how many years? \\
\hline$\ldots \ldots \ldots \ldots \ldots \ldots$ (years) \\
\hline$\ldots \ldots \ldots \ldots \ldots \ldots \ldots$ (years) \\
\hline$\ldots \ldots \ldots \ldots \ldots \ldots$ (years) \\
\hline$\ldots \ldots \ldots \ldots \ldots \ldots$ (years) \\
\hline
\end{tabular}

9. Highest educational qualification completed:

\begin{tabular}{|l|l|}
\hline Bachelors (BA, B.Tech, etc.) / Higher Diploma & I \\
\hline Honours & 2 \\
\hline Masters (M.Sc, M.Tech, etc.) & 3 \\
\hline Doctorate (Ph.D, D.Tech, etc.) & 4 \\
\hline
\end{tabular}

I0. Gender:

\begin{tabular}{|l|l|}
\hline Female & I \\
\hline Male & 2 \\
\hline
\end{tabular}

II. Year of birth: 19.

In order to complete Section B, please select one research project that meets the following criteria:

- The project was completed in the last five years (completion here means that results or findings have been generated, and that the project has been reported on)

- You were the primary/principal investigator or project leader on the project

- You devoted significant research time and resources to the project.

The project you select could either be a stand-alone research study or a project within a longer-term research programme. 


\section{B. RESEARCH PROJECT}

12. Title:

13. Please give a brief description of the research topic (e.g. the quantification of resistances to blood flow in the lower limb arterial system using an inverse transmission line model; current trends in the selection of students for Higher Education, etc.)

14. In which broad research domain(s) do the research activities mainly fall? (Tick all applicable categories.)

\begin{tabular}{|l|l|}
\hline Agricultural sciences & $\mathrm{I}$ \\
\hline Applied sciences and technologies & 2 \\
\hline Arts and humanities & 3 \\
\hline Biological sciences & 4 \\
\hline Chemical sciences & 5 \\
\hline Earth sciences & 6 \\
\hline Economic and management sciences & 7 \\
\hline Engineering sciences & 8 \\
\hline Environmental sciences & 9 \\
\hline Health sciences & 10 \\
\hline Information and communication technologies & 11 \\
\hline Marine sciences & 12 \\
\hline Material sciences & 13 \\
\hline Mathematical sciences & 14 \\
\hline Medical sciences: basic & 15 \\
\hline Medical sciences: clinical & 16 \\
\hline Physical sciences & 17 \\
\hline Social sciences & 18 \\
\hline $\begin{array}{l}\text { Other } \\
\text { (Specify: ..............................................) }\end{array}$ & 19 \\
\hline
\end{tabular}

15. What triggered the research? (Tick all applicable statements.)

\begin{tabular}{|l|l|}
\hline Previous research by yourself & $\mathrm{I}$ \\
\hline Own curiosity or research interest & 2 \\
\hline Colleague(s) approaching you to form part of a team & 3 \\
\hline An outside firm/company/institution approaching you & 4 \\
\hline Own interpretation of the immediate/ future environment & 5 \\
\hline A funding agency requesting proposals & 6 \\
\hline A tender/ contract research & 7 \\
\hline $\begin{array}{l}\text { Other } \\
\text { (Specify: .........................................................) }\end{array}$ & $\mathbf{8}$ \\
\hline
\end{tabular}

16. (a) When (in which year) did the project start? (year)

(b) When (in which year) did it end? (year) 
17. Approximately what proportion of your research time did you devote to this project?

\begin{tabular}{|l|l|l|l|l|l|l|l|l|l|}
\hline $10 \%$ & $20 \%$ & $30 \%$ & $40 \%$ & $50 \%$ & $60 \%$ & $70 \%$ & $80 \%$ & $90 \%$ & $100 \%$ \\
\hline & & & & & & & & & \\
\hline
\end{tabular}

18. (a) How much funding (grants, awards, contracts) did you receive for the project in total?

\begin{tabular}{|l|l|}
\hline Less than R250 000 & I \\
\hline R250 000-R499 000 & 2 \\
\hline R500 000-R999 000 & 3 \\
\hline RI 000 000-RI 999 000 & 4 \\
\hline R2 000 000-R5 000 000 & 5 \\
\hline More than R5 000 000 & 6 \\
\hline
\end{tabular}

(b) Please tick the major source(s) of funding:

\begin{tabular}{|c|c|}
\hline Parliamentary grant & $\mathrm{I}$ \\
\hline Business contract & 2 \\
\hline Government contract & 3 \\
\hline Sale of goods & 4 \\
\hline 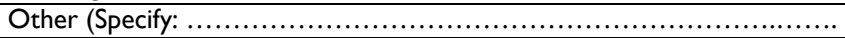 & 5 \\
\hline
\end{tabular}

19. Did you collaborate with others on the project? Please indicate in which sectors they work. (Tick all applicable categories.)

\begin{tabular}{|l|l|}
\hline Other science councils & $\mathrm{I}$ \\
\hline Universities & 2 \\
\hline Technikons & 3 \\
\hline Government & 4 \\
\hline NGOs & 5 \\
\hline Industry/ business & 6 \\
\hline Intended user(s) & 7 \\
\hline Other (Specify: $\ldots \ldots \ldots \ldots \ldots \ldots \ldots \ldots \ldots \ldots \ldots \ldots \ldots \ldots \ldots \ldots \ldots \ldots \ldots \ldots \ldots \ldots \ldots \ldots \ldots \ldots \ldots \ldots \ldots \ldots \ldots \ldots \ldots \ldots \ldots$ \\
\hline
\end{tabular}

20. Which THREE of the following best describe the overall expected value/ outcome of the research? Also rate the extent to which you believe that the these, have been attained or not.

\begin{tabular}{|l|l|}
\hline & \\
& \\
& \\
\hline Advancement or improvement in knowledge & $\mathrm{I}$ \\
\hline Solving of theoretical problems & 2 \\
\hline Solving immediate technical or applied problems & 3 \\
\hline Solving environmental or social problems & 4 \\
\hline Development of skills and competencies & 5 \\
\hline Training of students & 6 \\
\hline Change in behaviour/ attitudes/ values & 7 \\
\hline Influenced decision-makers & 8 \\
\hline Change legislation & 9 \\
\hline Development of new technology & 10 \\
\hline Improved product or technical design & 11 \\
\hline Engineered a prototype & 12 \\
\hline Entrance into new markets & 13 \\
\hline $\begin{array}{l}\text { Other } \\
\text { (Specify: ................................................) }\end{array}$ & 14 \\
\hline
\end{tabular}

\begin{tabular}{|c|c|c|}
\hline 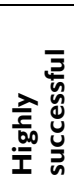 & 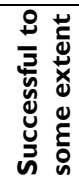 & 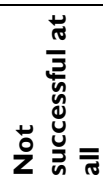 \\
\hline I & 2 & 3 \\
\hline I & 2 & 3 \\
\hline I & 2 & 3 \\
\hline I & 2 & 3 \\
\hline I & 2 & 3 \\
\hline I & 2 & 3 \\
\hline I & 2 & 3 \\
\hline I & 2 & 3 \\
\hline I & 2 & 3 \\
\hline I & 2 & 3 \\
\hline $\mathrm{I}$ & 2 & 3 \\
\hline $\mathrm{I}$ & 2 & 3 \\
\hline I & 2 & 3 \\
\hline I & 2 & 3 \\
\hline
\end{tabular}


21. Which intended beneficiaries did you have in mind when you conceptualised the research? (Tick all applicable categories.)

\begin{tabular}{|c|c|}
\hline $\begin{array}{l}\text { Colleagues/ scholars/ peers in own discipline } \\
\text { (Specify: } \ldots \ldots \ldots \ldots \ldots \ldots \ldots\end{array}$ & $\mathrm{I}$ \\
\hline 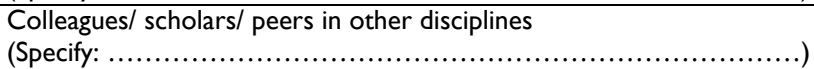 & 2 \\
\hline $\begin{array}{l}\text { The contracting agency } \\
\text { (Specify: } \ldots \ldots \ldots \ldots \ldots \ldots \ldots \ldots \ldots \ldots \ldots \ldots \ldots \ldots \ldots \ldots \ldots \ldots \ldots \ldots \ldots \ldots \ldots \ldots)\end{array}$ & 3 \\
\hline 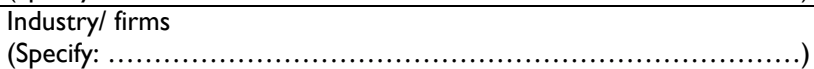 & 4 \\
\hline $\begin{array}{l}\text { Government } \\
\text { (Specify: } \ldots \ldots \ldots \ldots \ldots \ldots \ldots \ldots \ldots \ldots \ldots \ldots \ldots \ldots \ldots \ldots \ldots \ldots \ldots \ldots \ldots \ldots \ldots \ldots \ldots \ldots \ldots\end{array}$ & 5 \\
\hline $\begin{array}{l}\text { Specific interest groups (e.g. farmers, consumers) } \\
(\text { Specify: } \ldots \ldots \ldots \ldots \ldots \ldots \ldots \ldots \ldots \ldots \ldots \ldots \ldots \ldots \ldots \ldots \ldots \ldots \ldots \ldots \ldots \ldots \ldots \ldots \ldots \ldots \ldots \ldots \ldots \ldots \ldots \ldots \ldots\end{array}$ & 6 \\
\hline General public/ society/ community & 7 \\
\hline 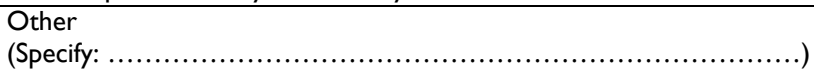 & 8 \\
\hline
\end{tabular}

22. Have the intended beneficiaries recognised/ utilised/ implemented the research as planned?

\begin{tabular}{|l|l|}
\hline Yes, to some extent & I \\
\hline Yes, to little extent & 2 \\
\hline No, not at all & 3 \\
\hline Don't know & 4 \\
\hline
\end{tabular}

If yes (some/ little extent), please answer Question 23 and go to Question 25.

If no, please go to Question 24.

If you don't know, please go to Question 25.

23. Please describe how the research has been utilised/ implemented/ applied by the intended beneficiaries. (Give concrete examples.)

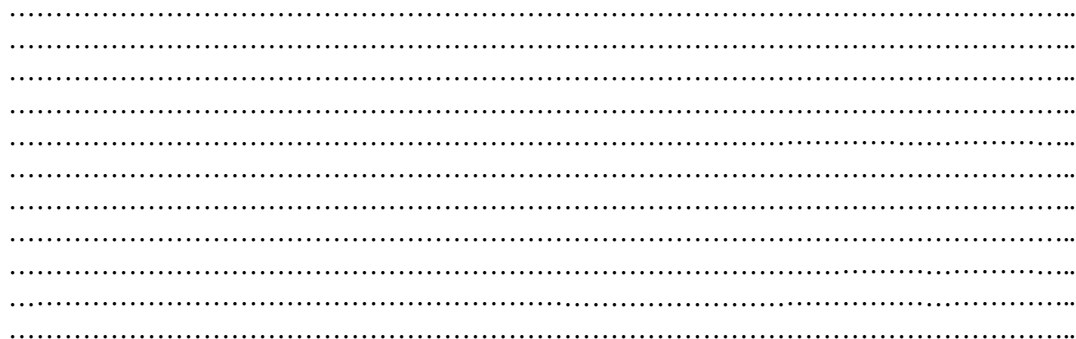

\section{Go to Question 25.}

24. In your opinion, why hasn't the research been utilised/ implemented/ applied by the intended beneficiaries as planned? 
25. What form of support did you give to the intended beneficiaries? (Training, writing a manual, etc.)

26. How did you communicate the results of your research? (Please indicate the mode of communication as well as the number of outputs - i.e. the number of articles, reports, books, patents, licenses and workshops that resulted from this project directly or indirectly.)

\begin{tabular}{|c|c|c|}
\hline Publications and documents & Yes & No \\
\hline Articles in refereed scientific journals & $\mathrm{I}$ & 2 \\
\hline Articles in refereed technical journals & I & 2 \\
\hline Articles in popular journals & $\mathrm{I}$ & 2 \\
\hline Contract reports & I & 2 \\
\hline Books/ monographs & $\mathrm{I}$ & 2 \\
\hline Chapters in books & $\mathrm{I}$ & 2 \\
\hline Published conference proceedings & $\mathrm{I}$ & 2 \\
\hline Written input to official policy documents & $\mathrm{I}$ & 2 \\
\hline Technical manuals & I & 2 \\
\hline \multicolumn{3}{|l|}{ Presentations } \\
\hline Presentations to predominantly academic audiences & I & 2 \\
\hline Presentations to predominantly non-academic audiences & $\mathrm{I}$ & 2 \\
\hline Presentations to expert committees/ panels & $\mathrm{I}$ & 2 \\
\hline Presentations at public hearings & $\mathrm{I}$ & 2 \\
\hline Presentations at fairs/ exhibitions/ road shows & $\mathrm{I}$ & 2 \\
\hline \multicolumn{3}{|l|}{ Patents/ licences } \\
\hline Through patenting & $\mathrm{I}$ & 2 \\
\hline Through licensing & $\mathrm{I}$ & 2 \\
\hline \multicolumn{3}{|l|}{ Training and supervision } \\
\hline Training through workshops & $\mathrm{I}$ & 2 \\
\hline Training through coursework & $\mathrm{I}$ & 2 \\
\hline Supervision of masters and doctoral students & $\mathrm{I}$ & 2 \\
\hline \multicolumn{3}{|l|}{ Cooperative interactions and informal meetings } \\
\hline Consultations/ technical assistance to potential users & $\mathrm{T}$ & 2 \\
\hline Personnel exchanges/ secondments & $\mathrm{I}$ & 2 \\
\hline Informal meetings with potential users/ teams & $\mathrm{I}$ & 2 \\
\hline \multicolumn{3}{|l|}{ Organisational structures } \\
\hline Through participation in consortia & I & 2 \\
\hline Through science parks & I & 2 \\
\hline Through spin-off companies & I & 2 \\
\hline Through technology transfer offices & I & 2 \\
\hline Through technology incubators & $\mathrm{I}$ & 2 \\
\hline $\begin{array}{l}\text { Other } \\
\text { (Specify: } \ldots \ldots \ldots \ldots \ldots \ldots \ldots \ldots \ldots \ldots \ldots \ldots \ldots \ldots \ldots \ldots \ldots)\end{array}$ & $\mathrm{I}$ & 2 \\
\hline
\end{tabular}
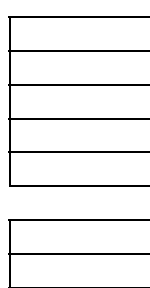

Training and supervision

Training through workshops

raining through coursework

Supervision of masters and doctoral stud

Consultations/ technical assistance to potential users

ersonnel exchanges/ secondments

Through participation in consortia

Through science parks

hrough spin-off companies

Through technology transfer offices

Other

27. How many postgraduate students received their degree through the research project? . (number of masters students)

(number of doctoral students) 
28. (a) Have there been any unintended beneficiaries of your research?

\begin{tabular}{|l|l|}
\hline Yes & I \\
\hline No & 2 \\
\hline Don't know & 3 \\
\hline
\end{tabular}

(b) If yes, please describe (i) who the unintended beneficiaries are and (ii) how they have utilised/ implemented/ applied the research.

(i)

(ii)

29. Is there anything else that you would like to raise? Anything not covered by this questionnaire or maybe something about the questionnaire itself?

THANK YOUR VERY MUCH FOR YOUR TIME AND EFFORT

THE END 

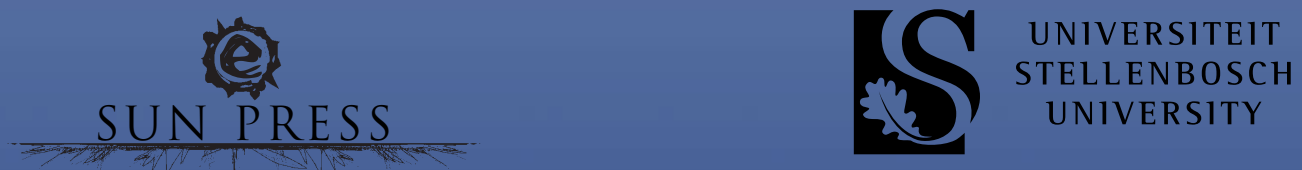